$\mathrm{DOE} / \mathrm{ER} / 14180--3$

DE93 009760

\title{
APPLICATION OF MAGNETOMECHANICAL HYSTERESIS MODELING OF MAGNETIC TECHNIQUES FOR MONITORING NEUTRON EMBRITTLEMENT AND BIAXIAL STRESS
}

\section{SECOND YEAR INTERIM REPORT June 1992 - Dec 1992}

M.J. Sablik, H. Kwun, and G. L. Burkhardt,

Southwest Research Institute

San Antonio, TX 78228-0510

January 31,1993

PREPARED FOR THE U.S. DEPARTMENT OF ENERGY

UNDER GRANT NUMBER DE-FG05-91ER14180

WroteR

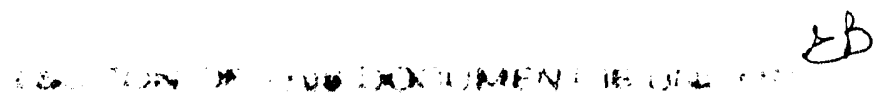




\begin{abstract}
The objectives of this project are (1) to evaluate magnetic measurement methods for their ability to detect neutron embrittlement and biaxial stress in steel and (2) to understand how neutron embrittlement and biaxial stress affect the magnetic properties of steel. These issues are important because of their relationship to safety in the nuclear power industry and in the gas and oil pipeline industry.

This technical progress report refers to research on the biaxial stress problem accomplished in the first half of the second year. All of the work done was preparatory to magnetic measurements. Issues addressed were: (1) construction of a model for extracting changes in the magnetic properties of a specimen from the readings of an indirect sensor; (2) initial development of a model for how biaxial stress alters the intrinsic magnetic properties of the specimen; (3) use of finite element stress analysis modeling to determine a detailed shape for the cruciform biaxial stress specimen; (4) construction of the biaxial stress loading apparatus.

In the remainder of the second year, additional analysis will use the sensor model to help choose a sensor design, and then, finally, magnetic measurements will be made of hysteresis loop parameters and of the higher order harmonics of the hysteresis loop. Modeling biaxial stress effects on magnetic properties will continue into the third year, and analysis will address issues that will ultimately lead to a synthesis of several modeling approaches. Also, in the third year, the MIVC, Barkhausen and magabsorption techniques will be evaluated experimentally and theoretically for their ability to detect biaxial stress. Finally, the modeling will return to neutron embrittlement and address similarities and differences between neutron embrittlement and creep damage insofar as effects on magnetic properties are concerned.
\end{abstract}


I. INTRODUCTION $\ldots \ldots \ldots \ldots \ldots \ldots \ldots \ldots \ldots \ldots \ldots \ldots \ldots \ldots \ldots \ldots \ldots \ldots$

II. MODELING RESULTS FOR EFFECT OF BLAXIAL STRESS ON TEST SPECIMEN'S MAGNETIC PROPERTIES $\ldots \ldots \ldots \ldots \ldots \ldots \ldots \ldots \ldots$

A. Results from Magnetomechanical Hysteresis Modeling $\ldots \ldots \ldots \ldots \ldots$

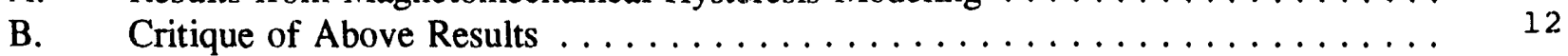

C. A Modified Schneider-Kashiwaya Model of Biaxial Stress $\ldots \ldots \ldots \ldots \ldots \ldots$

III. PROBLEM OF INTERPRETATION OF DATA FROM INDIRECT

MAGNETIC SENSORS $\ldots \ldots \ldots \ldots \ldots \ldots \ldots \ldots \ldots \ldots \ldots \ldots \ldots$

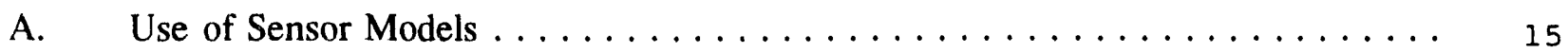

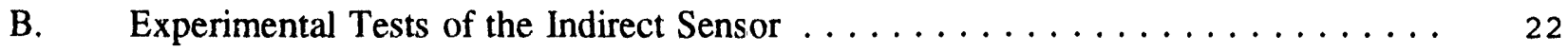

IV. SPECIMEN SHAPE DESIGN VIA FINITE ELEMENT MODELING $\ldots \ldots \ldots \ldots \ldots$

V. CONSTRUCTION OF THE BIAXIAL LOADING APPARATUS $\ldots \ldots \ldots \ldots$

VI. SUMMARY AND DISCUSSION OF FUTURE PLANS $\ldots \ldots \ldots \ldots \ldots \ldots \ldots$

A. $\quad$ Experimental $\ldots \ldots \ldots \ldots \ldots \ldots \ldots \ldots \ldots \ldots \ldots \ldots \ldots$

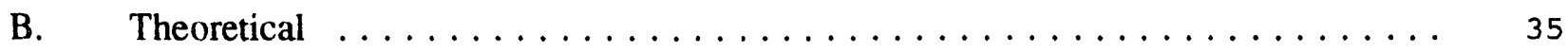

A. Paper by M.J. Sablik and D.C. Jiles, entitled "Coupled Magnetoelastic Theory of Magnetic and Magnetostrictive Hysteresis," submitted to IEEE Transactions on Magnetiss

B. Paper by M.J. Sablik, S.W. Rubin, L.A. Riley, D.C. Jiles, D. A. Kaminski, and S.B. Biner, entitled "A Model for Hysteretic Magnetic Properties Under the Application of Noncoaxial Stress and Field," submitted to Journal of Applied Physics

C. Draft of paper entitled, "A Modified Schneider - Kashiwaya Model for the Effects of Biaxial Stress on Magnetic Properties," to be submitted to the Journal of Magnetism and Magnetic Materials 


\section{FIGURE CAPTIONS}

$\underline{\text { Page }}$

Fig. 1 Computed results for magnetic properties (a) $B_{\max } / \mu_{0} H_{\max }$, (b) $B_{r} / B_{\max }$,

(c) $\mathrm{H}_{d} / \mathrm{H}_{\max }$ and (d) $\mu_{c}$, the permeability at $\mathrm{H}=\mathrm{H}_{\mathrm{c}}$, all as a

function of $\sigma_{1}-v \sigma_{2}$, where $\sigma_{1}$ is stress along axis $1, \sigma_{2}$ is stress

along perpendicular axis 2 , and $v$ is Poisson's ratio. In this case,

the magnetic field is parallel to axis 1 .

Fig. 2 Computed results for (a) $B_{\max } / \mu_{o} H_{\max }$, (b) $B_{r} / B_{\max }$, (c) $H_{c} / H_{\max }$ and (d) $\mu_{c}$ all as a function of $\sigma_{2}-v \sigma_{1}$. For this case, the magnetic field is perpendicular to axis 1 and parallel to axis 2 .

Fig. 3 Computed results for (a) $\left(\mathrm{B}_{\max } / \mu_{\mathrm{o}} \mathrm{H}_{\max }\right)_{\perp}-\left(\mathrm{B}_{\max } / \mu_{0} \mathrm{H}_{\max }\right)_{l}$,

(b) $\left(B_{r} / B_{\max }\right)_{\perp}-\left(B_{r} / B_{\max }\right)_{l}$, (c) $\left(H_{d} / H_{\max }\right)_{\perp}-\left(H_{d} / H_{\max }\right)_{l}$,

(d) $\left(\mu_{c}\right)_{\perp}-\left(\mu_{c}\right)_{1}$ all of a function of the stress difference

$\sigma_{2}-\sigma_{1}$. Here ()$_{1}$ is the value of the property when $H$ is

parallel to axis 1 and ()$_{\perp}$ is the value when $H$ is perpendicular

to axis 1 and parallel to axis 2 .

Fig. 4

Computed results for (a) $\left(B_{\max } / \mu_{0} H_{\max }\right)_{\perp}-\left(B_{\max } / \mu_{0} H_{\max }\right)_{l}$,

(b) $\left(B_{r} / B_{\max }\right)_{\perp}-\left(B_{r} / B_{\max }\right)_{l}$, (c) $\left(H_{d} / H_{\max }\right)_{\perp}-\left(H_{c} / H_{\max }\right)_{l}$,

(d) $\left(\mu_{c}\right)_{\perp}-\left(\mu_{c}\right)_{1}$ all as a function of stress sum $\sigma_{1}+\sigma_{2}$.

As seen in the figure, there is no clearly defined functional

relationship.

Fig. 5 Computed results for (a) $B_{\max } / \mu_{o} H_{\max }$, (b) $B_{r} / B_{\max }$, (c) $H_{d} / H_{\max }$ and (d) $\mu_{c}$ all as a function of $\sigma_{1}+\sigma_{2}$. In this case, $\mathrm{H}$ is at $45^{\circ}$ with respect to both axis 1 and axis 2 .

Fig. 6 Diagram of sensor used for basic sensor model (after Fleming ${ }^{62}$ ).

Fig. 7 Diagrams of various lengths and distances associated with the sensor pole configuration. (after Fleming ${ }^{62}$ ) 19

Fig. 8 Flux paths from core arm to specimen as categorized into three regions.

Fig. 9 Diagram of alternative sensor design where the excitation coil is across both sensor arms.

Fig. 10 Diagram of Kashiwaya et al's cruciform specimen. (after Kashiwaya ${ }^{52}$ )

Fig. 11 Stress distribution for the Kashiwaya cruciform obtained via finite element modeling in the case when the arms are loaded biaxially with equal stress. 
Fig. 12 Side view of an alternative cruciform design, showing the stress distribution in the z-direction perpendicular to the plane of the cruciform in the case of equal biaxial loading.

Fig. 13 Stress distribution for $\sigma_{x x}$ in the plane of the cruciform for the case of the alternative cruciform design and equal biaxial loading.

Fig. 14 Stress distribution for $\sigma_{y y}$ in the plane of the cruciform for the case of the alternative cruciform design and equal biaxial loading.

Fig. 15 Distribution of the ratio $\sigma_{y y} / \sigma_{x x}$ in the central region of the alternative cruciform in the case of equal biaxial loading.

Fig. 16

Biaxial stressing fixture designed for this project. 


\section{INTRODUCTION}

This research project focuses on two areas of nondestructive evaluation (NDE) relating to safety in the energy industry:

(1) The problem of nondestructively monitoring neutron embrittlement in nuclear pressure vessels; and

(2) The problem of nondestructively detecting and quantifying high stress levels in gas and oil pipeline, where both hoop and longitudinal stresses co-exist in a biaxial stress condition.

These research problems are important because cf the need to prevent structural failure of (1) nuclear pressure vessels and (2) oil and gas pipelines.

In the first year, the focus was on the problem of magnetic detection of neutron embrittlement of pressure vessel steel. In the second year, the concern shifts to work related to magnetic measurement of biaxial stress. Thus, the discussion in this report is almost exclusively concerned with biaxial stress detection, which is pertinent to detection of stress in pipelines. The reader is referred to the first-year report for discussion of neutron embrittlement detection.

Magnetic detecrion of stress in steel is accomplished by applying a magnetic field, and sensing changes in the magnetic flux density caused by the stress. In detecting biaxial stress in steel, one is restricted to using a sens "- which is placed on the steel surface and which indirectly detects changes in the flux density caused oy the stress in the material. The sensor typically consists of (1) an excitation coil wound around a magnetic core which is used to magnetize the material and (2) a sensing coil also wound around the core which is used to detect, indirectly, changes in the magnetic properties of the material by sensing changes in the magnetic flux going through it. A direct reading of change in flux density through the specimen could be made by drilling holes in a part of the specimen, and by threading a sensing coil through the holes; however, this kind of direct sensor is not practical to use, because the holes would tend to alter the stress distribution in the specimen.

In interpreting the data taken by the indirect sensor, one needs to know how to separate the changes due to the magnetic properties of the steel specimen from the contributions arising from the sensor core and the geometric configuration of the sensor. Thus, interpretation of indirect sensor data is a problem which must receive attention during this second phase of the project, particularly if we are to understand how biaxial stress affects the intrinsic magnetic properties of the specimen.

Understanding how biaxial stress alters the intrinsic magnetic properties of a polycrystalline steel specimen has been an open question. Most of the physical modeling ${ }^{1-19}$ and experimental work ${ }^{20-}$ ${ }^{40}$ dealing with the effect of stress on magnetic properties has centered on the effect of uniaxial stress. Until recently, very little work has been done on biaxial stress effects on magnetic properties. Experimental work has clarified some of the basic magnetic behavior. ${ }^{41-50}$ However, models for magnetic behavior under biaxial stress have been restricted to that published by Schneider and Richardson ${ }^{51}$ and, more recently, by Kashiwaya. ${ }^{52.53}$ In both these models, a number of deficiencies exist. In this project, the aim is to improve on the Schneider and Kashiwaya models and amalgamate the results to an extension of the Sablik-Jiles mode $\left.\right|^{8-15.17 .18}$ to biaxial stress. The resulting model could then make predictions about magnetic behavior under biaxial stress, which could be tested 
experimentally and which could be used to suggest ways of magnetically measuring both biaxial strress components.

Another problem that requires attention before experiments can be done is how to design the experimental setup for measuring magnetic changes due to biaxial stress. Our original proposal suggested using a cruciform specimen in the shape of a cross with arms of equal length; biaxial stresses would be applied by pulling or pushing on the specimen arms. This is the most general way to study biaxial stress. In setting up to do this, we therefore first focussed on design considerations pertaining to the shape of the specimen. The detailed cruciform shape had to result in (1) assurance that there is a reasonably uniform stress distribution in the center of the test piece when equal biaxial stresses are applied to the arms and (2) avoidance of sharp concentrations of stress that would cause the specimen to deform and fail before a desirable stress level could be established in the central area of the specimen. Two different cruciform shapes were evaluated using finite element stress analysis modeling. The shape selection was to be based on which of the two cruciform shapes had the more desirable stress distribution.

A fourth problem in preparation for the biaxial stress measurements is construction of the cruciform loading apparatus itself.

In summary, the discussion in the body of this report deals with work done during the first part of the year on the following four issues:

(1) Modeling the effect of biaxial stress on specimen magnetic properties;

(2) Modeling to extract specimen magnetic property changes from measurements with an indirect sensor;

(3) Using finite element stress analysis modeling to select a cruciform specimen shape having a desirable stress distribution;

(4) Constructing the biaxial loading apparatus.

In the latter half of this year, specimens will be fabricated and magnetic property changes in these specimens under biaxial stress will be measured using an indirect magnetic sensor and using an appropriate algorithm for extracting the actual specimen's magnetic properties from the changes seen with the sensor. At the same time, magnetic property modeling for steels under biaxial stress will continue, with the results from the final model tested against the experimental measurements. The experimental measurements are expected to provide (1) data on magnetic property changes in hysteresis loop parameters, such as coercivity, remanence, and maximum differential permeability, and (2) data on changes in the nonlinear harmonic amplitudes. In the third year, the effect of biaxial stress will be measured using Barkhausen noise, magnetically induced velocity change (MIVC), and magabsorption techniques. (See the first year report for a description of these techniques) Modeling at that time will address those aspects of the problem. 


\section{MODELING RESULTS FOR EFFECT OF BIAXIAL STRESS ON TEST SPECIMEN'S MAGNETIC PROPERTIES}

\section{A. Results from Magnetomechanical Hysteresis Modeling}

Magnetomechanical hysteresis modeling is a modeling approach that we have proposed to use for the treatment of biaxial stress. Up to this point, the approach has been used only to describe magnetic property changes under uniaxial stress.

The magnetomechanical hysteresis model was explained in Appendix A in our original proposal. ${ }^{54}$ Modeling added to the model to properly treat the coupling of magnetization to magnetostriction was discussed in Appendix B of that proposal. An important modification to the discussion in Appendix B of that proposal is presented in the paper by Sablik and Rubin ${ }^{15}$. The entire development has since been written up as a full paper and submitted for publication. ${ }^{18}$ The full paper is attached as Appendix A of this report. It should be noted that all this work treats the effect of stress on magnetic properties when magnetic field and stress axis are aligned (i.e. are coaxial).

Another modeling paper, completed under a project with the Electric Power Research Institute, treats the case where magnetic field and stress axis are noncoaxial. This paper ${ }^{19}$ is found in Appendix $\mathrm{B}$ of this report.

In extending the magnetomechanical hysteresis model to biaxial stress, results from the paper in Appendix B will be employed. In particular, in that paper, it is shown that the effect of an external field $\vec{H}$ and uniaxial stress $\sigma$ is to introduce into the macroscopic material an overall effective field given by

$$
H_{e}=H \cos \beta+\alpha M_{a}+H_{\sigma}
$$

where $\beta$ is the angle between the external field direction and the direction of the macroscopic magnetization, $\alpha$ is a constant describing coupling between interacting domains, and $H_{\sigma}$ is the overall macroscopic stress molecular field given by

$$
H_{\sigma}=\frac{3}{2} \frac{\sigma}{\mu_{o}} \frac{\partial \lambda}{\partial M_{a}}\left(\cos ^{2} \phi-v \sin ^{2} \phi\right) .
$$

In this expression, $\phi$ is the angle between stress axis and magnetization direction, $\mu_{0}$ is the permeability of free space, $v$ is Poisson's ratio ${ }^{5,18.55}$, and $\lambda$ is the total macroscopic magnetostriction (or the change in length divided by the original length in the direction of the stress axis, produced by magnetization of the material). $\mathrm{M}_{\mathrm{a}}$ is the anhysteretic magnetization (or magnetization if the system were in its thermodynamic equilibrium state, which is attainable by adding an a.c. magnetic field of decreasing amplitude per cycle to external bias field $H$ ). $M_{a}$ is given by 


$$
M_{a}=M_{s} L\left(H_{e} / a\right)
$$

where $M_{s}$ is the saturation magnetization, $a$ is the effective field normalization constant, and $L(x)$ is the Langevin function, ${ }^{56}$ given by $L(x)=\cos x-1 / x$.

Hysteresis enters through the irreversible contribution $\mathrm{M}_{i}$ to the magnetization, which arises because of domain wall pinning. This contribution is given via a differential equation which must be solved numerically. This equation is

$$
\frac{d M_{i}}{d H}=\frac{\left(M_{a}-M_{i}\right) \cos \beta}{\frac{k \delta}{\mu_{o}}-\left[\alpha+\frac{3}{2} \frac{\sigma}{\mu_{o}} \frac{\partial^{2} \lambda}{\partial M_{a}^{2}}\left(\cos ^{2} \phi-v \sin ^{2} \phi\right)\right]\left(M_{a}-M_{i}\right)}
$$

where $\mathrm{k}$ is the pinning constant and $\delta= \pm 1$ (depending on whether $\mathrm{H}$ is increasing or decreasing). The total magnetization is then obtained from

$$
M=M_{i}+c\left(M_{a}-M_{i}\right)
$$

where the second term in the sum is a contribution due to domain wall bowing (which is a reversible contribution). The constant $\mathrm{c}$ is the ratio between the slope of the initial magnetization curve and the slope of the anhysteretic magnetization curve as the system magnetizes initially from the demagnetized state. The magnetostriction $\lambda$ appearing in eqs. (2) and (4) is actually just the anhysteretic contribution to the magnetostriction, which is given, as a function of $M_{a}$, by the following:

$$
\frac{3}{2} \lambda=\frac{b}{|b|}\left\{\sqrt{\left(\frac{3}{2} \frac{b_{\phi}}{Y}\right)^{2}+\frac{2}{Y}\left(\frac{1}{2} \alpha \mu_{o}\left(M_{s}^{2}-M_{a}^{2}\right)\right)}-\sqrt{\left(\frac{2}{3} \frac{b_{\phi}}{Y}\right)^{2}+\frac{\alpha \mu_{o}}{Y} M_{s}^{2}}\right\},
$$

where $\mathrm{Y}$ is Young's modulus ${ }^{5,18.55}, \mathrm{~b}$ is the magnetoelastic coupling constant, ${ }^{5,14,15}$ and

$$
b_{\phi}=b(1+v)\left(1-\frac{3}{2} \sin ^{2} \phi\right)
$$

Eq. (1)-(7) briefly describe the magnetomechanical hysteresis model for the ferromagnetic material under uniaxial stress and magnetic field where stress and field are noncoaxial. 
To treat biaxial stress, the next step was to extend the above uniaxial model for noncoaxial stress and field. We now describe the path of extension that we took.

Following the lead of Schneider and Richardson ${ }^{51}$, it was deemed reasonable that in the biaxial stress case, the two stresses could be treated as if they were linearly superposed in the stress terms contributing to the model. Thus, under biaxial stresses $\sigma_{1}$ and $\sigma_{2}$ and with $M$ at an angle $\phi$ with respect to the $\sigma_{1}$-axis and at angle $(\pi / 2)-\phi$ with respect to the $\sigma_{2}$-axis, one finds for the effective field $\mathrm{H}_{\mathrm{e}}$ the following result:

$$
H_{e}=H \cos (\theta-\phi)+\alpha M_{a}+\frac{3}{2 \mu_{o}} \frac{\partial \lambda}{\partial M_{a}}\left[\sigma_{1}\left(\cos ^{2} \phi-v \sin ^{2} \phi\right)+\sigma_{2}\left(\sin ^{2} \phi-v \cos ^{2} \phi\right)\right],
$$

where $\theta$ is the angle between the magnetic field $\vec{H}$ and the $\sigma_{1}$-axis. The resulting expression for irreversible contribution $\mathrm{M}_{i}$ is therefore given via

$$
\frac{d M_{i}}{d H}=\frac{\left(M_{a}-M_{i}\right) \cos (\theta-\phi)}{\frac{k \delta}{\mu_{o}}-F_{B}\left(\sigma_{1}, \sigma_{2}, \phi\right)\left(M_{a}-M_{i}\right)},
$$

where

$$
F_{B}\left(\sigma_{1}, \sigma_{2}, \phi\right)=\alpha+\frac{3}{2 \mu_{o}} \frac{\partial^{2} \lambda}{\partial M_{a}^{2}}\left[\sigma_{1}\left(\cos ^{2} \phi-v \sin ^{2} \phi\right)+\sigma_{2}\left(\sin ^{2} \phi-v \cos ^{2} \phi\right)\right],
$$

The anhysteretic magnetization and total magnetization are obtained as in eqs. (3) and (5) respectively.

In the limit as $\theta, \phi \rightarrow 0$, so that $\vec{H}$ is aligned with the $\sigma_{1}$-axis, we find that

$$
H_{e}=H_{e}^{(1)} \equiv H+\alpha M_{a}+\frac{3}{2 \mu_{o}} \frac{\partial \lambda\left(\phi=0^{\circ}\right)}{\partial M_{a}}\left[\sigma_{1}-v \sigma_{2}\right]
$$

and 


$$
F_{B}\left(\sigma_{1}, \sigma_{2}, 0^{\circ}\right)=\alpha+\frac{3}{2 \mu_{o}} \frac{\partial^{2} \lambda\left(\phi=0^{\circ}\right)}{\partial M_{a}^{2}}\left[\sigma_{1}-v \sigma_{2}\right]
$$

In the limit as $\theta, \phi \rightarrow 90^{\circ}$, so that $\vec{H}$ is perpendicular to the $\sigma_{1}$-axis and parallel to the $\sigma_{2}$-axis, we find that

$$
H_{e}=H_{e}^{(\perp)} \equiv H+\alpha M_{a}+\frac{3}{2 \mu_{o}} \frac{\partial \lambda\left(\phi=90^{\circ}\right)}{\partial M_{a}}\left[\sigma_{2}-v \sigma_{i}\right]
$$

and

$$
F_{B}\left(\sigma_{1}, \sigma_{2}, 90^{\circ}\right)=\alpha+\frac{3}{2 \mu_{o}} \frac{\partial^{2} \lambda\left(\phi=90^{\circ}\right)}{\partial M_{a}^{2}}\left[\sigma_{2}-v \sigma_{1}\right]
$$

To obtain information about the biaxial stresses, one can manipulate eqs. (8)-(12). Some interesting results have been found in the case of the approximation that $\theta=\phi$ (which, strictly speaking, is not true. See Fig. 3a in Appendix B).

Hysteresis loops were computed for a test case with $\theta=\phi$. The following values were taken for the magnetic parameters - namely, $\mathrm{M}_{\mathrm{s}}=1.61 \times 10^{6} \mathrm{~A} / \mathrm{m}, a=4500 \mathrm{~A} / \mathrm{m}, \mathrm{k} / \mu_{\circ}=3000 \mathrm{~A} / \mathrm{m}$, and $c=0.1$. The elastic constant $c_{11}=1.26 \times 10^{8} \mathrm{kN} / \mathrm{m}^{2}$ and $c_{12}=4.8 \times 10^{7} \mathrm{kN} / \mathrm{m}^{2}$ were used ${ }^{5,18}$ to compute Young's modulus and the Poisson ratio. The magnetoelastic constant $b$ was taken to be $-0.242 \times 10^{4} \mathrm{kN} / \mathrm{m}^{2}$. The values for the elastic and magnetoelastic constants are consistent with that of iron. ${ }^{5}$

From the computed hysteresis loops, various magnetic properties were obtained, such as maximum flux density $B_{\max }$ at maximum field $H_{\max }$, remanence $B_{r}$, coercive field $H_{c}$, and differential permeability $\mu_{c}=(d M / d H)_{H=H_{c}}$ evaluated at the coercive field.

Fig. 1 shows the computed magnetic properties for the case of $\theta=0^{\circ}$, so that $H$ is parallel to the $\sigma_{1}$-axis. The figure shows (a) $B_{\max } / \mu_{o} H_{\max }$, (b) $B_{r} / B_{\max }$, (c) $H_{d} / H_{\max }$ and (d) $\mu_{c}$ all as a function of $\sigma_{1}-v \sigma_{2}$, as described by eqs. (11). With the exception of $\mu_{c}$, all of the properties display an almost linear relationship with $\sigma_{1}-v \sigma_{2}$. This might be a little surprising, since the total magnetization is a rather complicated function of $\sigma_{1}-v \sigma_{2}$, as seen in eqs. (3), (5), (8)-(10).

Fig. 2 shows the computed magnetic properties for the case of $\theta=90^{\circ}$. This time, the figure shows (a) $B_{\max } / \mu_{0} H_{\max }$, (b) $B_{r} / B_{\max }$, (c) $H_{c} / H_{\max }$ and (d) $\mu_{c}$ all as a function of $\sigma_{2}-v \sigma_{1}$, as described by 


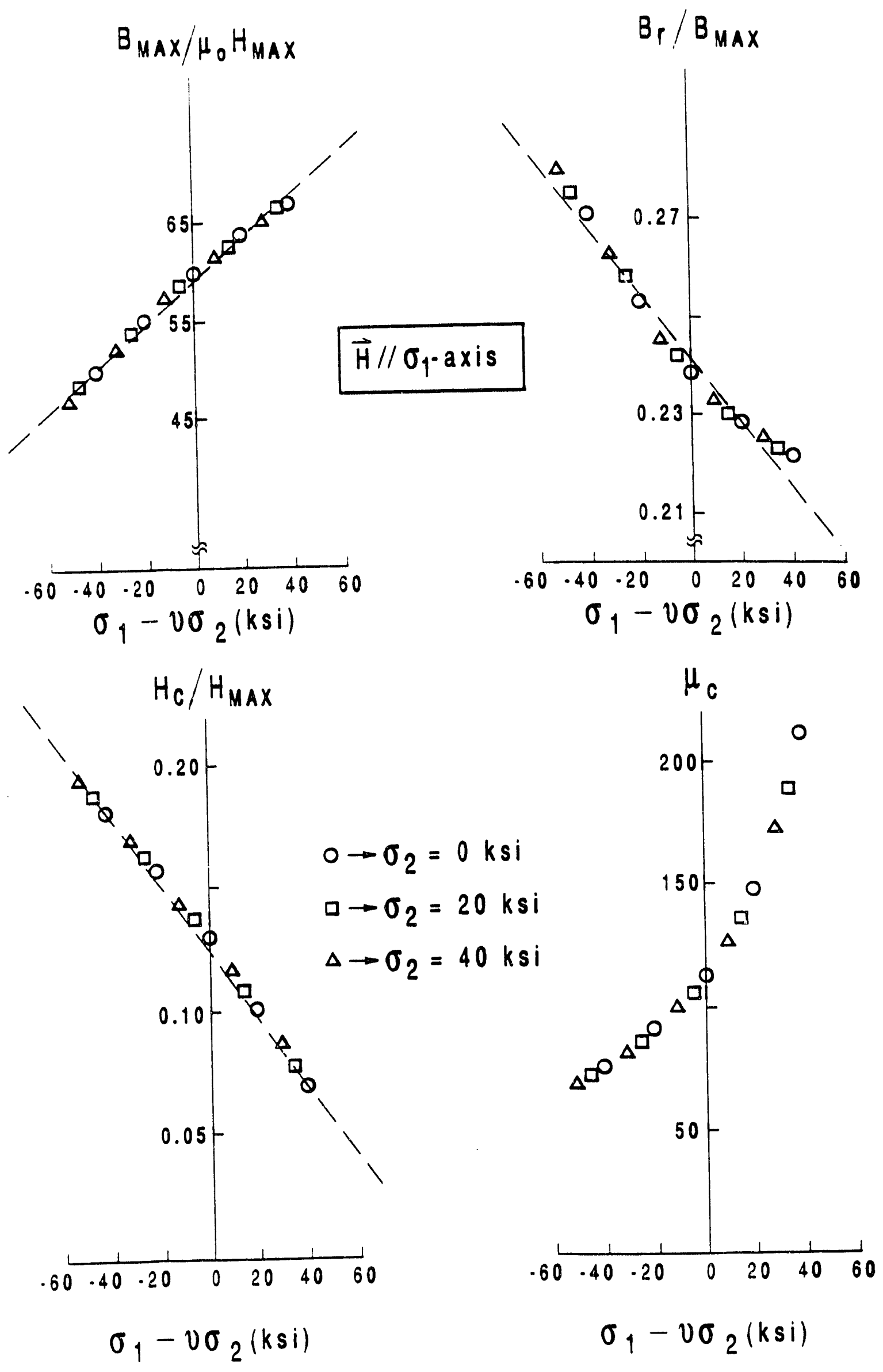

Fig. 1 Computed results for magnetic properties (a) $B_{\operatorname{mad}} / \mu_{0} H_{\max }$, (b) $B_{\sqrt{ }} / B_{\max }$, (c) $H_{c} / H_{\max }$ and (d) $\mu_{c}$, the permeability at $\mathrm{H}=\mathrm{H}_{c}$, all as a function of $\sigma_{1}-v \sigma_{2}$, where $\sigma_{1}$ is stress along axis $1, \sigma_{2}$ is stress along perpendicular axis 2 , and $v$ is Poisson's ratio. In this case. the magnetic field is parallel to axis 1. , 


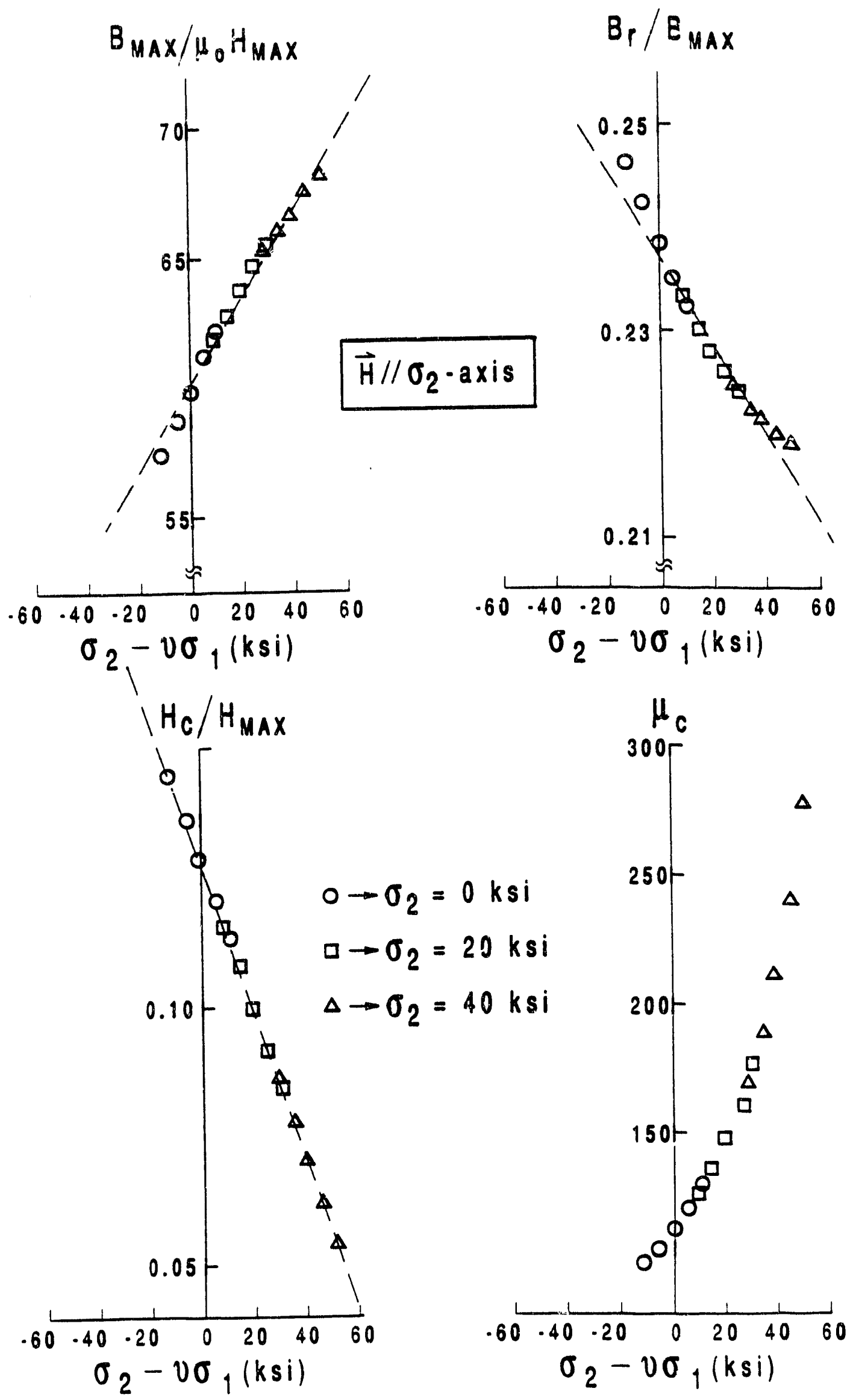

Fig. 2 Computed resuits for (a) $\overline{\mathrm{B}}_{\operatorname{ma}} / \mu_{\mathrm{o}} \mathrm{H}_{\max }$ (b) $\mathrm{B}_{\mathrm{f}} / \mathrm{B}_{\max }$, (c) $\mathrm{H} j / \mathrm{H}_{\max }$ and (d) $\mu_{\mathrm{c}}$ aii as a function of $\sigma_{2}-v \sigma_{1}$. For this case, the magnetic field is perpendicular to axis 1 and parallel to axis 2 . 
eqs. (12). With the exception of $\mu_{c}$, all of the properties display an almost linear relationship with $\sigma_{2}-v \sigma_{1}$.

To eliminate the need for knowing Poisson's ratio $v$, it was thought that perhaps a linear combination of the two cases might be useful. Thus, we considered that

$$
H_{e}^{(\perp)}-H_{e}^{(1)}=\frac{3}{2 \mu_{o}} \frac{\partial \lambda}{\partial M_{a}}(1+v)\left(\sigma_{2}-\sigma_{1}\right)
$$

if one used the approximation that $b_{\phi}=b(1+v)$ and ignored the $\phi$-dependence of $\lambda$. Eq. (13) suggested that it might be reasonable to expect that the difference between the magnetic property values when $\theta=0^{\circ}$ and when $\theta=90^{\circ}$ might tum out to be a linear function of $\sigma_{2}-\sigma_{1}$.

Fig. 3 shows the computed results for (a) $\left(B_{\max } / \mu_{d} / H_{\max }\right)_{\perp}-\left(B_{\max } / \mu_{0} H_{\max }\right)_{l}$, (b) $\left(B_{r} / B_{\max }\right)_{\perp}-$ $\left(B_{r} / B_{\max }\right)_{l}$, (c) $\left(H_{d} / H_{\max }\right)_{\perp}-\left(H_{d} / H_{\max }\right)_{1}$, and $(d)\left(\mu_{c}\right)_{\perp}-\left(\mu_{c}\right)_{1}$ all as a function of the stress difference $\sigma_{2}-\sigma_{1}$, but without using the approximation that $b_{\phi}=b(1+v)$. Here ()$_{1}$ is the value of the property when $\theta=0^{\circ}$ so that $\mathrm{H}$ is aligned with $\sigma_{1}$; similarly ()$_{\perp}$ is the value of the property when $\theta=90^{\circ}$, or $\mathrm{H}$ is aligned with $\sigma_{2}$. It is seen that except for permeability, all of the differences, ()$_{\perp}-()_{1}$, display an almost linear relationship with stress difference $\sigma_{2}-\sigma_{1}$.

An additional combination was also tried, namely that the sum ()$_{\perp}+()_{1}$ was also computed for each of the properties. From eq. (11) and (12), the prediction is that

$$
H_{e}^{(\perp)}+H_{e}^{(1)}=2 H+\alpha\left(M_{a}^{(1)}+M_{a}^{(1)}\right)+\frac{3}{2 \mu_{o}} \frac{\partial \lambda}{\partial M_{a}}(1-v)\left(\sigma_{2}+\sigma_{1}\right)
$$

This is more complicated than eq. (13), and one might suspect that the sum ()$_{\perp}+()_{1}$ might not be an almost linear function of $\sigma_{2}+\sigma_{1}$. Fig. 4 affirms this to be the case.

Thus, it appears so far that we can use the magnetic properties to obtain the stress difference $\sigma_{2}-\sigma_{1}$

The experimental work of Buttle et $\mathrm{al}^{47}$ suggests that magnetic techniques such as Barkhausen noise emission, magnetoacoustic emission, and the rotation method of Langman ${ }^{58,59}$ can all be used to obtain the stress difference $\sigma_{2}-\sigma_{1}$. Our computed results in Fig. 3 are a prediction that stress difference $\sigma_{2}-\sigma_{1}$ ought to be obtainable from basic hysteresis loop parameters as well. properties.

It remains to be seen if the stresses $\sigma_{1}$ and $\sigma_{2}$ can be determined individually from magnetic

An approach that could be used for this latter purpose is to orient $H$ so that $\theta=45^{\circ}$. If one then uses the approximation that $\phi=\theta=45^{\circ}$, then one has 


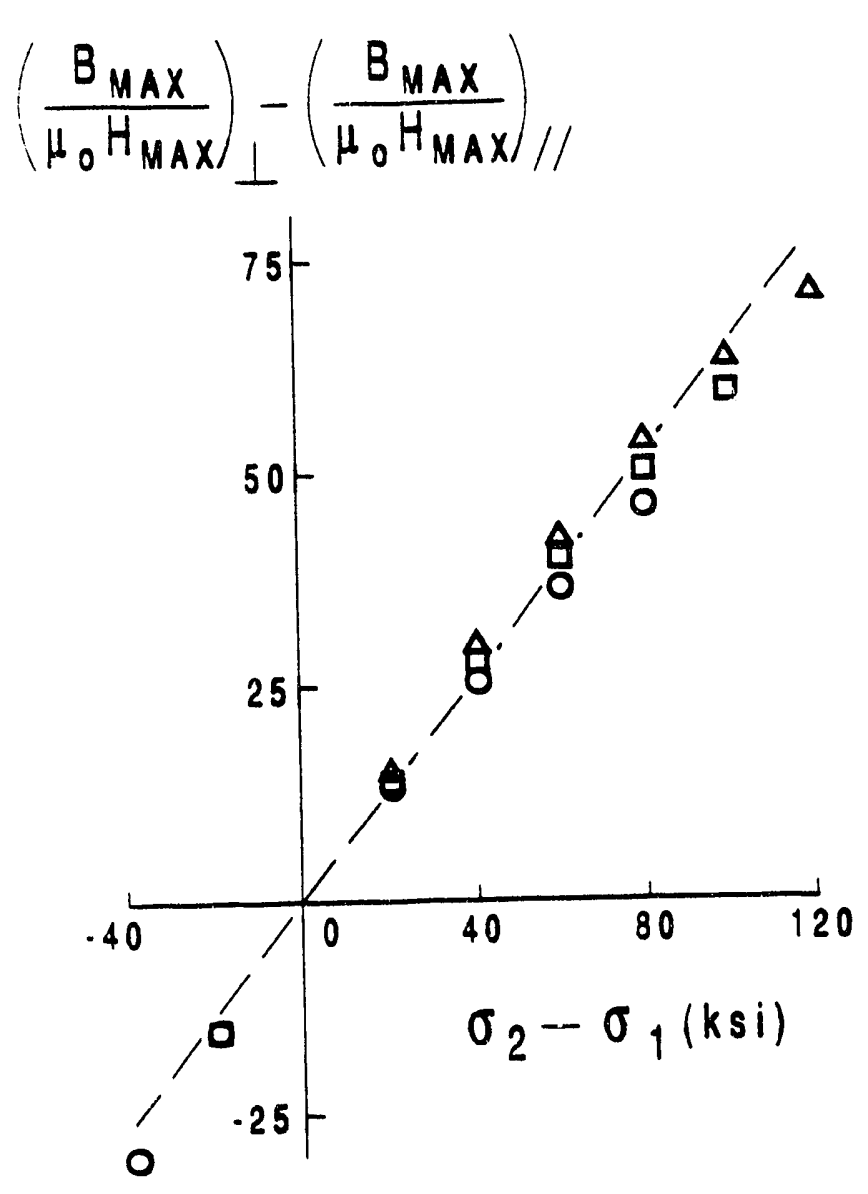

$$
\left(\frac{B_{r}}{B_{\text {MAX }}}\right)_{\perp}-\left(\frac{B_{r}}{B_{\text {MAX }}}\right)_{/ /}
$$
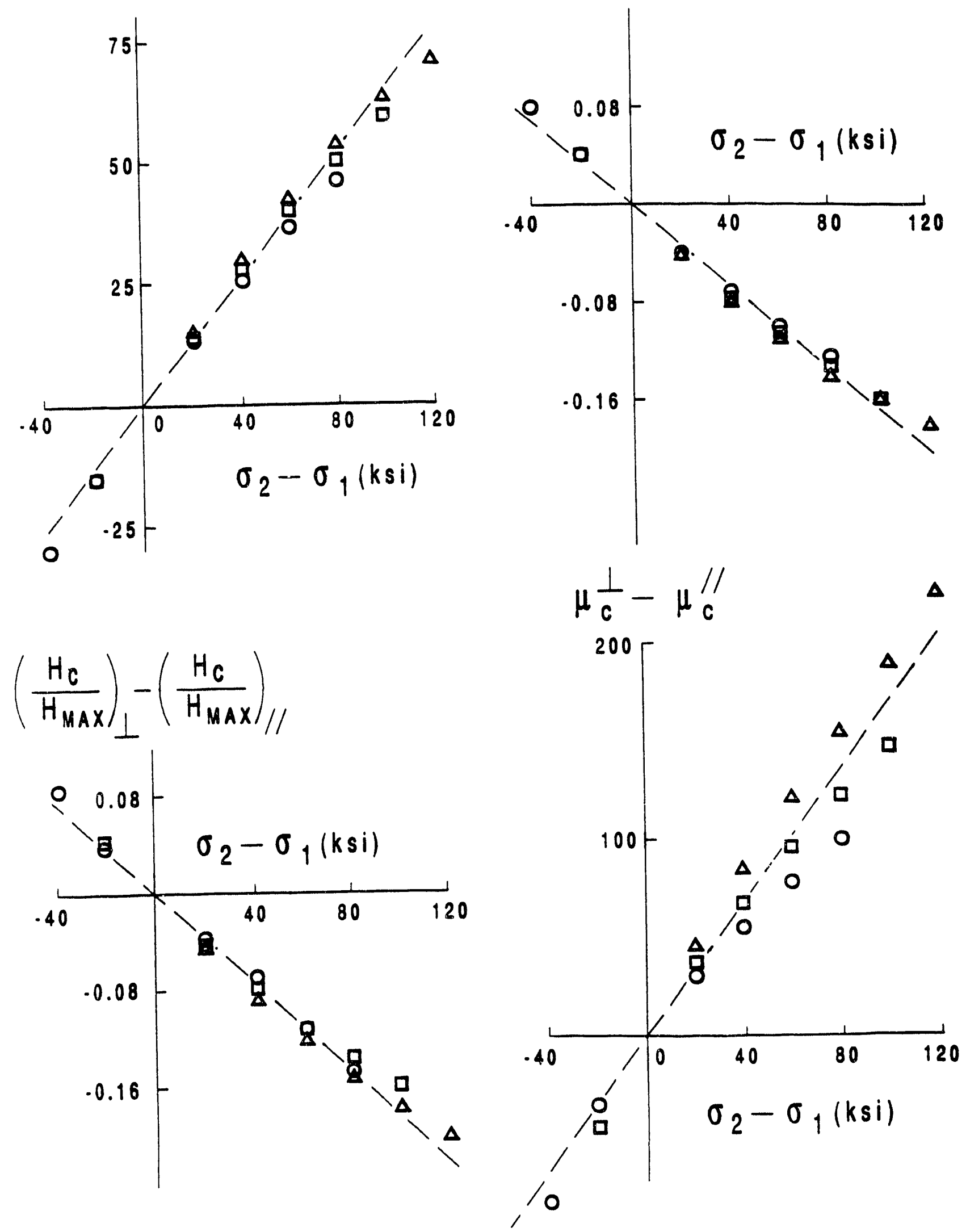

Fig. 3 Computed results for (a) $\left(B_{\max } / \mu_{0} H_{\max }\right)_{\perp}-\left(B_{\operatorname{mad}} / \mu_{0} H_{\max }\right)_{1}$, (b) $\left(B_{\sqrt{m a x}} / B_{1}-\left(B_{1} / B_{\operatorname{man}}\right)_{1}\right.$, (c) $\left(\mathrm{H}_{\delta} / \mathrm{H}_{\mathrm{ma}}\right)_{\perp}-\left(\mathrm{H}_{\delta} / \mathrm{H}_{\text {max }}\right)_{1},(\mathrm{~d})\left(\boldsymbol{H}_{c}\right)_{\perp}-\left(\mu_{c}\right)_{8}$ all of a function of the istress difference $\sigma_{2}-\sigma_{1}$. Here ()$_{1}$ is the value of the property when $H$ is parallel to axis 1 and ()$_{\perp}$ is the value when $H$ is perpendicular to axis 1 and parallel to axis 2 . 


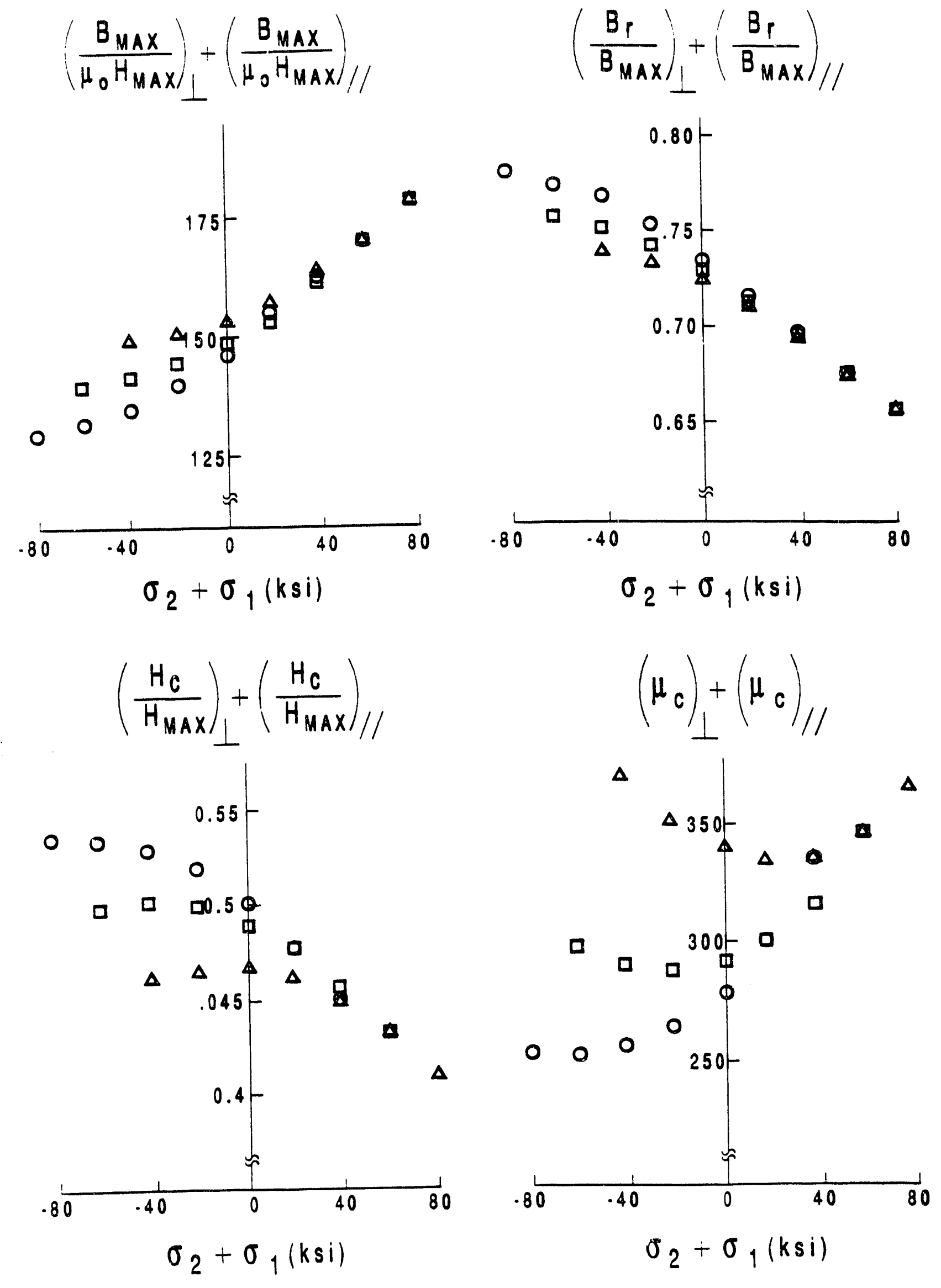

Fig. 4

Computed results for (a) $\left(\mathbf{B}_{\max } / \mu_{0} H_{\max }\right)_{\perp}-\left(\mathbf{B}_{\max } / \mu_{0} H_{\max }\right)_{1}$, (b) $\left(B_{1} / B_{\max }\right)_{\perp}-\left(B_{1} / B_{\max }\right)_{1}$, (c) $\left(\mathrm{H}_{c} / \mathrm{H}_{\max }\right)_{l}-\left(\mathrm{H}_{c} / \mathrm{H}_{\operatorname{man}}\right)_{4}$, (d) $\left(\mu_{c}\right)_{1}-\left(\mu_{c}\right)_{1}$ all as a function of stress sum $\sigma_{1}+\sigma_{2}$. As seen in the figure, there is no clearly defined functional relationship. 


$$
H_{e}^{\left(45^{\circ}\right)}=H+\alpha M_{a}^{\left(45^{\circ}\right)}+\frac{3}{2 \mu_{o}} \frac{\partial \lambda^{45^{\circ}}}{\partial M_{a}}\left[\frac{1}{2}\left(\sigma_{2}+\sigma_{1}\right)\right](1-v),
$$

which suggests that magnetic property values with the magnetic field oriented at $45^{\circ}$ might be an almost linear function of $\sigma_{2}+\sigma_{1}$.

Fig. 5 shows the values of the magnetic properties when $\mathrm{H}$ is at $45^{\circ}$ with respect to the $\sigma_{1^{-}}$ and $\sigma_{2}$ - axes. Clearly, all the properties, even the permeability $\mu_{c}$ at the coercive field $H_{c}$, are almost linear functions of $\sigma_{2}+\sigma_{1}$, suggesting that the sum $\sigma_{2}+\sigma_{1}$ is attainable from the magnetic properties.

If one can find $\sigma_{2}-\sigma_{1}$ and one can find $\sigma_{2}+\sigma_{1}$, then by adding and subtracting, one can find $\sigma_{1}$ and $\sigma_{2}$. The prediction is therefore that from the magnetic properties, one ought to be able to determine both biaxial stresses.

Thus, in doing experimental measurements, the prediction is that one should look at three cases:

(1) $\mathrm{H} \| \sigma_{1}, \mathrm{H} \perp \sigma_{2}$

(2) $\mathrm{H} \perp \sigma_{1}, \bar{H} \| \sigma_{2}$

(3) $\mathrm{H}$ at $45^{\circ}$ with respect to $\sigma_{1}-$ and $\sigma_{2}$ - axes

and that by appropriate combinations of the measurements, one should be able to determine both $\sigma_{1}$ and $\sigma_{2}$.

\section{B. Critique of Above Results}

The above results do not suggest that compressive biaxial stresses intrinsically behave differently from tensile biaxial stresses or from cases where one of the stresses is tensile and the other compressive. The same mathematical result applies to all cases in the model. Thus, the only difference between a tensile and a compressive stress is the difference in sign, as far as the model is concerned. In recent papers, Kashiwaya et $\mathrm{al}^{43,44.52}$ have found experimentally a somewhat different picture, noting for example large changes in magnetic properties under biaxial compression but smaller changes under biaxial tension.

To explain his experimental observations, Kashiwaya ${ }^{52}$ proposed a different model for magnetic property changes under stress. In particular, Kashiwaya proposed that if the magnetic field is parallel to stress axis $\sigma_{i}$, then the magnetic property change is determined by stress change $\sigma_{i}-\sigma_{\max }$, where $\sigma_{\max }$ is the largest or principal stress. According to this model, this means that no further magnetic changes will occur if the field points in the direction of the principal stress axis. This is obviously untrue, but nevertheless it is found experimentally that magnetic changes with the field in the principal stress direction are much smaller than magnetic changes with the field perpendicular to the principal stress direction. An obvious extension of Kashiwaya's model to compressive stresses would be to recognize that under negative compressive stresses, the largest or most positive stress would be along the zero-stress axis perpendicular to the two biaxial stress axes. In other words, for the compressive case, $\sigma_{\max }=0$ and $\sigma_{i}-\sigma_{\max }=\sigma_{i}$. This would then account for differences between compressive biaxial and tensile biaxial stresses. 

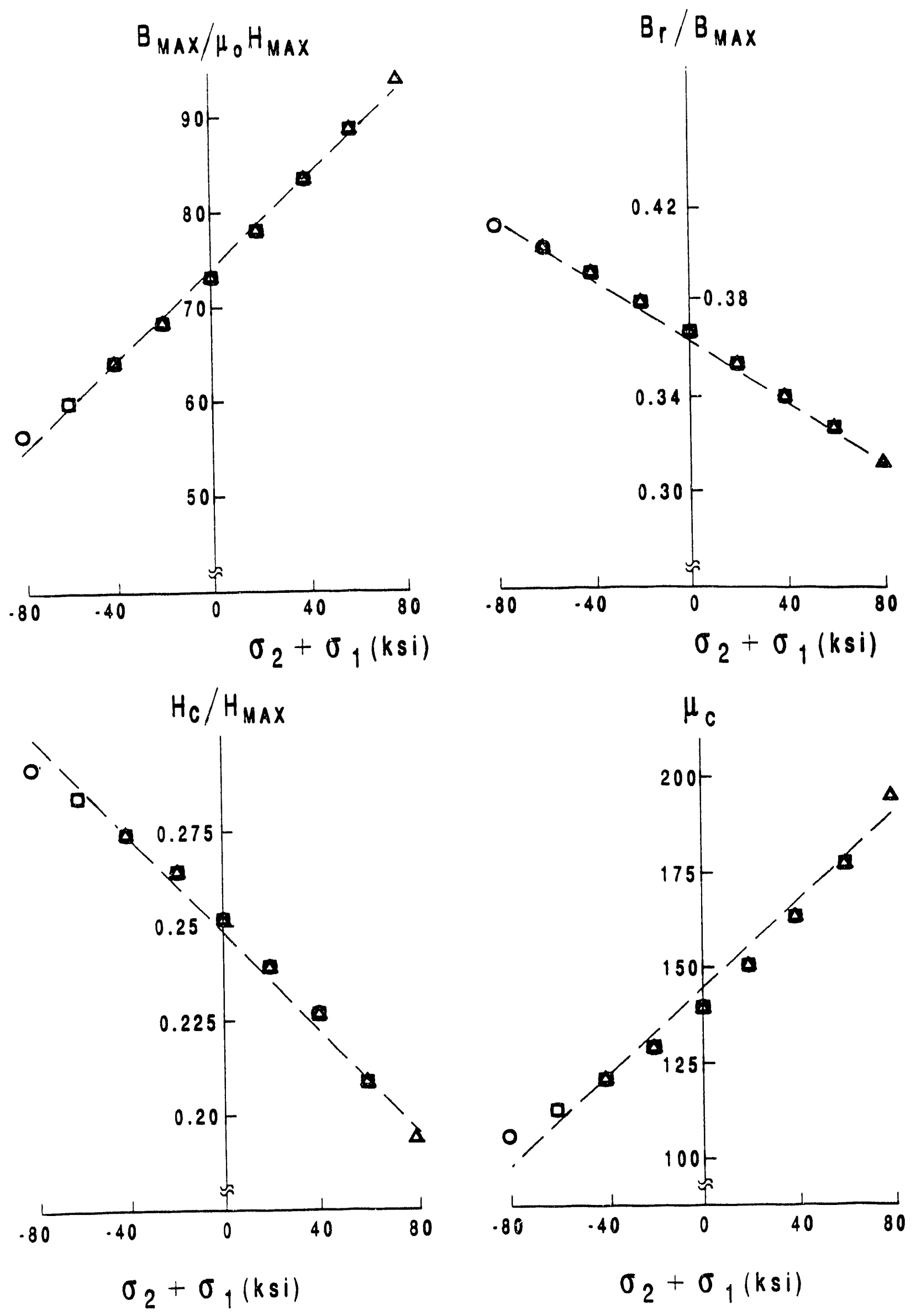

Fig. 5 Computed results for (a) $\mathrm{B}_{\max } / \mu_{0} \mathrm{H}_{\max }$, (b) $\mathrm{B}_{\sqrt{2}} / \mathrm{B}_{\max }$, (c) $\mathrm{H}_{0} / \mathrm{H}_{\max }$ and (d) $\mu_{\mathrm{c}}$ all as a function of $\sigma_{1}+\sigma_{2}$. In this case, $H$ is at $45^{\circ}$ with respect to both axis 1 and axis 2 . 
The challenge then is to find a way to accommodate Kashiwaya's model, within the framework of the magnetomechanical hysteresis model, and to see if the useful predictions of the present magnetomechanical hysteresis model still hold true in spite of the necessity to also accommodate the Kashiwaya model.

A second caveat about the magnetomechanical hysteresis model is that even under uniaxial stress, it lacks the ability to predict the Ewing/Villari effect, ${ }^{60,61}$ as presently formulated. The Ewing effect (often called the Villari effect) has to do with nonlinear behavior of the magnetic properties of steel as a function of tensile stress. In particular, for steels under different constant tensile stresses, magnetic properties like $B_{r}, B_{\max }$ or $\mu_{c}$ depart from an increasing linear dependence on stress at larger stresses and peak with increasing stress and start diminishing after that. A property like $\mathrm{H}_{c}$ decreases linearly at first with stress, reaches a minimum and starts increasing. This nonmonotonic behavior with tensile stress is not found in the present magnetomechanical hysteresis model.

It is believed that the Ewing/Villari behavior comes about because the magnetoelastic constant $\mathrm{b}$ itself is stress-dependent. This will affect the magnetostriction and the effective field variation with stress. An earlier model ${ }^{10}$ for the magnetostriction, with stress dependence in the magnetostriction similarly introduced, was indeed able to reproduce the Villari effect behavior.

It is clear that more modeling needs to be done.

\section{A Modified Schneider-Kashiwaya Model for Biaxial Stress}

Appendix $C$ contains a paper pertaining to work on yet another project, in which adjustments similar to those made by Kashiwaya, were inserted into the Schneider-Richardson model. ${ }^{51}$ A later model due to Schneider ${ }^{17}$ was actually used as a basis for the inclusion of some of Kashiwaya's ideas. The resulting model differs from that of Kashiwaya in that magnetic changes with the field in the principal stress direction are not zero, but are small compared to the case with the field perpendicular to the principal stress direction. Several other modifications are found in the model and the reader is referred to Appendix $\mathrm{C}$ for details.

The predicted results from this modified Kashiwaya-Schneider model compared very favorably to magnetic changes with biaxial stresses observed by Langman, who is a co-author of the paper.

The next step is to tie all three models together and provide a complete synthesis. This is obviously a challenging problem and will be addressed in further work on magnetomechanical hysteresis modeling in this project. 


\section{PROBLEM OF INTERPRETATION OF DATA FROM INDIRECT MAGNETIC SENSORS}

\section{A. Use of Sensor Models}

Since we are compelled to use an indirect sensor for measuring magnetic properties under biaxial stress, it is necessary to understand how to extract sample magnetic properties from measurements with the sensor. Fleming ${ }^{62-66}$ has provided a modeling approach that will enable us to address this problem. The approach is an electrical engineering approach, but it can be adapted to measurement of sample magnetic properties.

The basic model for the sensor consists of an excitation coil of $N_{1}$ turns and a detection coil of $\mathrm{N}_{2}$ turns. Each coil is wrapped around an arm of the C-core, as in Fig. 6. The C-core sensor is held close to the surface of the specimen with a small air gap between each arm and the specimen surface. The model takes into account the effect of the air gap and the effect of various flux leakages not going directly into the sample.

The measured quantity is called the sensor transfer impedance $Z$ and is defined as ${ }^{62}$

$$
Z=V_{2} / I_{1} \text {, }
$$

where $V_{2}$ is the detection coil output voltage amplitude and $I_{1}$ is the excitation coil input current amplitude. $\mathrm{Z}$ can also be shown to be

$$
Z=j X z
$$

where $\mathrm{j}$ is $\sqrt{-1}$ and where $\mathrm{X}$ is a mutual reactance parameter given by ${ }^{62}$

$$
X=\omega N_{1} N_{2} P \text {. }
$$

Here $\omega=2 \pi f$, where $f$ is a signal frequency. Mutual flux permeance $P$ can be shown to be ${ }^{62}$

$$
P=\frac{1}{R_{\text {gaps }}+R_{s}}=\frac{1}{\frac{1}{P_{\text {gaps }}}+\frac{1}{P_{s}}}
$$

$\Re_{\text {gaps }}$ is the total air gap reluctance and $\Re_{\mathrm{s}}$ is the reluctance of the flux-linked specimen. $\boldsymbol{P}_{\text {gaps }}$ refers to the total air gap permeance and $P_{s}$ is the effective permeance of the specimen to be sensed. The 


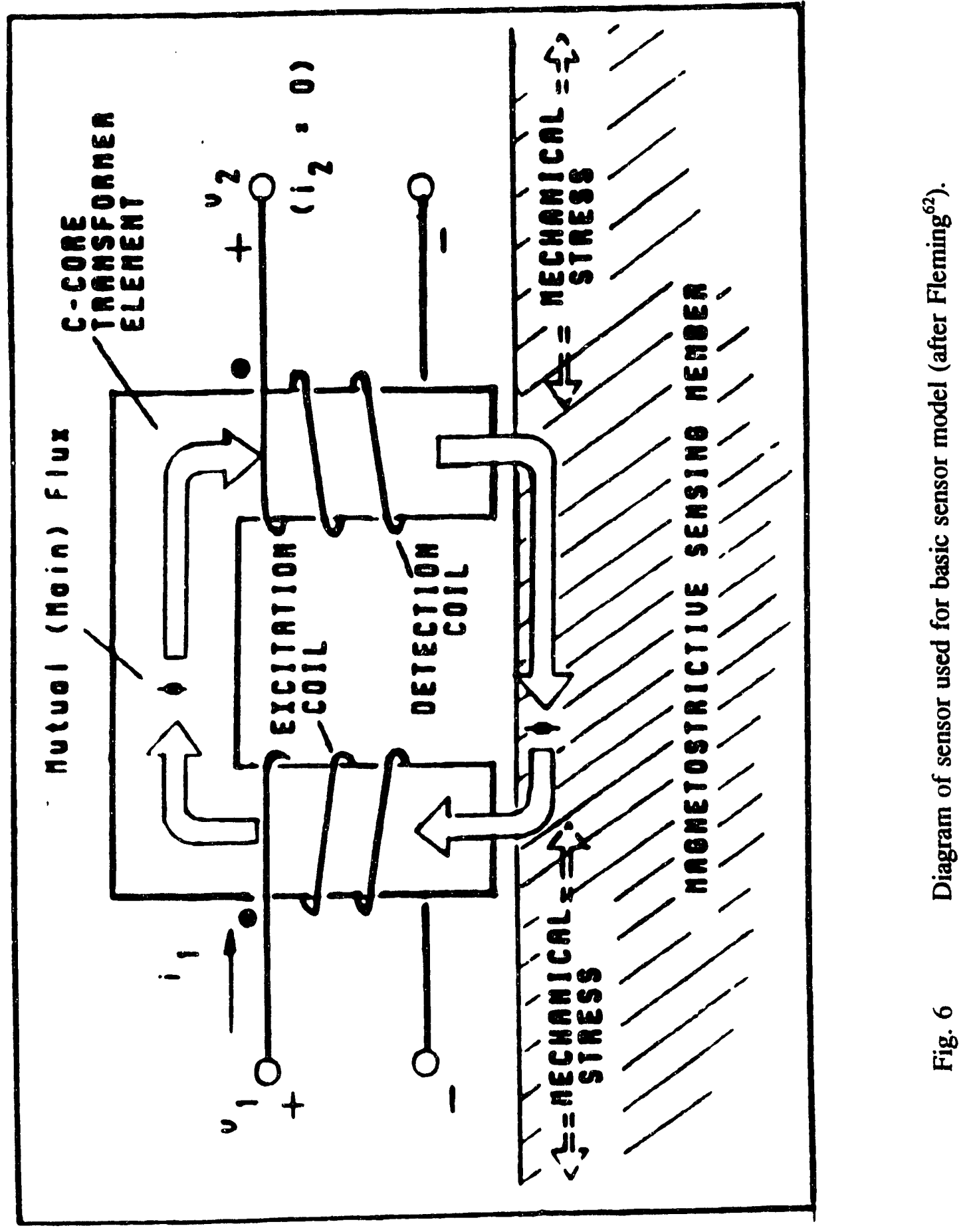


other quantity appearing in eq. (17) is $\mathrm{z}$, given by ${ }^{62}$

$$
z=p+\frac{x(1-j / \epsilon)}{1+x(1-j / \epsilon)}
$$

The quantities on the right hand side are defined $a s^{62}$

$$
\begin{gathered}
x=P_{3} / P, \\
p=\left(P_{12} / 3\right) / P, \\
\epsilon=\tan \theta_{3}=\omega L_{3 L} / R_{3} .
\end{gathered}
$$

Here $R_{3}$ is the electrical resistance of the sensed portion of the specimen, $L_{3 L}$ is its reactance, and $\theta_{3}$ is the corresponding phase angle. The angle $\theta_{3}$ is $45^{\circ}$ at low fields $s^{67,68}$ and as saturation approaches, the angle $\theta_{3}$ approaches $26^{\circ}$ at high fields. ${ }^{69,70} \rho_{12}$ is the cross leakage permeance and $P_{3}$ is given by ${ }^{62}$

$$
P_{3}=\frac{1}{\frac{1}{P_{s}}+\frac{1}{P_{3 A}}}
$$

where $P_{3 A}$ is the permeance of the eddy-current reaction flux $\phi_{3}$ generated in the specimen in accordance with Lenz Law. This flux $\phi_{3}$ acts in opposition to the flux sent into the specimen by the $C$-core. It is seen that, to use the model, we need to evaluate the permeances $P_{\text {gaps }}, P_{12}, P_{s}$, and $P_{3 A}$. Of these, the only one depending on the specimen's material magnetic properties is $P_{s}$.

Permeance $P_{s}$ can be expressed in terms of the permeability $\mu$ of the specimen. In particular,

$$
P_{s}=\mu \delta^{\prime} g(u)
$$

For uniform flux flow, 


$$
\delta^{\prime}=\delta / \sqrt{2}=\sqrt{\rho / 2 \pi f \mu}=\sqrt{\rho / \mu \omega},
$$

where $\rho$ is the electrical resistivity and $\delta$ is the skin depth. From (23) and (24), we see that $P_{s}$ is proportional to the square root of the permeability. The geometrical constant $g(u)$ is given by ${ }^{62}$

$$
g(u)=\frac{2 \pi}{\ln \left(u+\sqrt{u^{2}-1}\right)},
$$

where

$$
u=\frac{L^{2}-r_{B}^{2} r_{D}^{2}-r_{D}^{2}}{2 r_{E} r_{D}}
$$

is given in terms of the centerline distance L between sensor poles and where (see Fig. 7)

$$
\begin{aligned}
& r_{E}=\sqrt{A_{E} / \pi}=\sqrt{b_{E}^{2} / \pi}, \\
& r_{D}=\sqrt{A_{D} / \pi}=\sqrt{b_{D}^{2} / \pi},
\end{aligned}
$$

where if $b_{E}$ is the length or width of square pole face $E$, then $A_{E}$ is its area and $r_{E}$ is its effective pole face radius (see Fig. 7a). If $d_{0}$ is the distance between core arms, then $L$ is given by

$$
L=d_{0}+b_{E} / 2++b_{D} / 2
$$

Note that $P_{s}$ enters through eq. (19) into $X$ and through eq. (22) into $\mathrm{z}$ and that the transfer impedance is affected in two ways by $P_{s}$.

Since we can obtain an expression for permeability $\mu$ from the magnetomechanical hysteresis model or from the Schneider model, we have a way of predicting the transfer impedance. The way to obtain $\mathrm{Z}$ as a function of $\mathrm{H}$ would be to generate hysteresis loops of different maximum $\mathrm{H}$. The value of $\mu$ at each maximum $H$ would then be substituted into eqs. (23) and (24), and then, assuming 


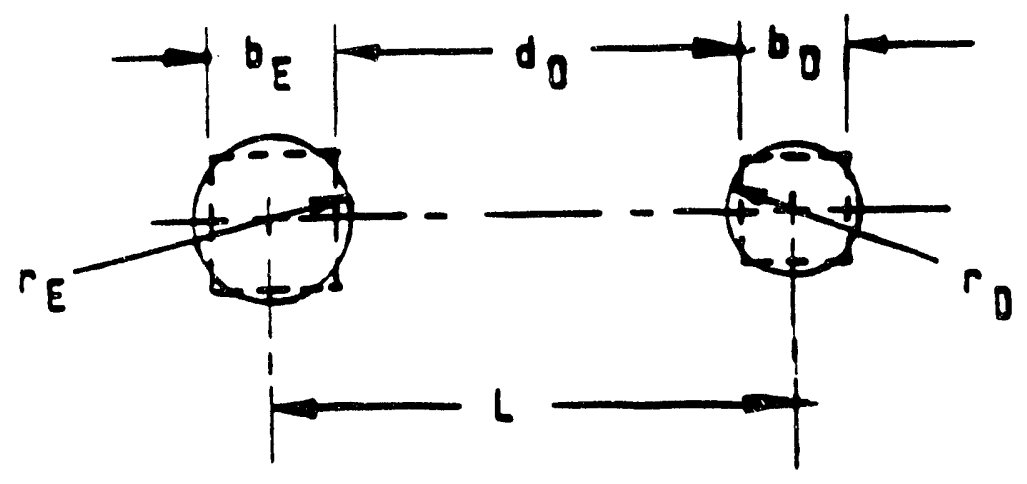

(a) POLE SEPARATIOA

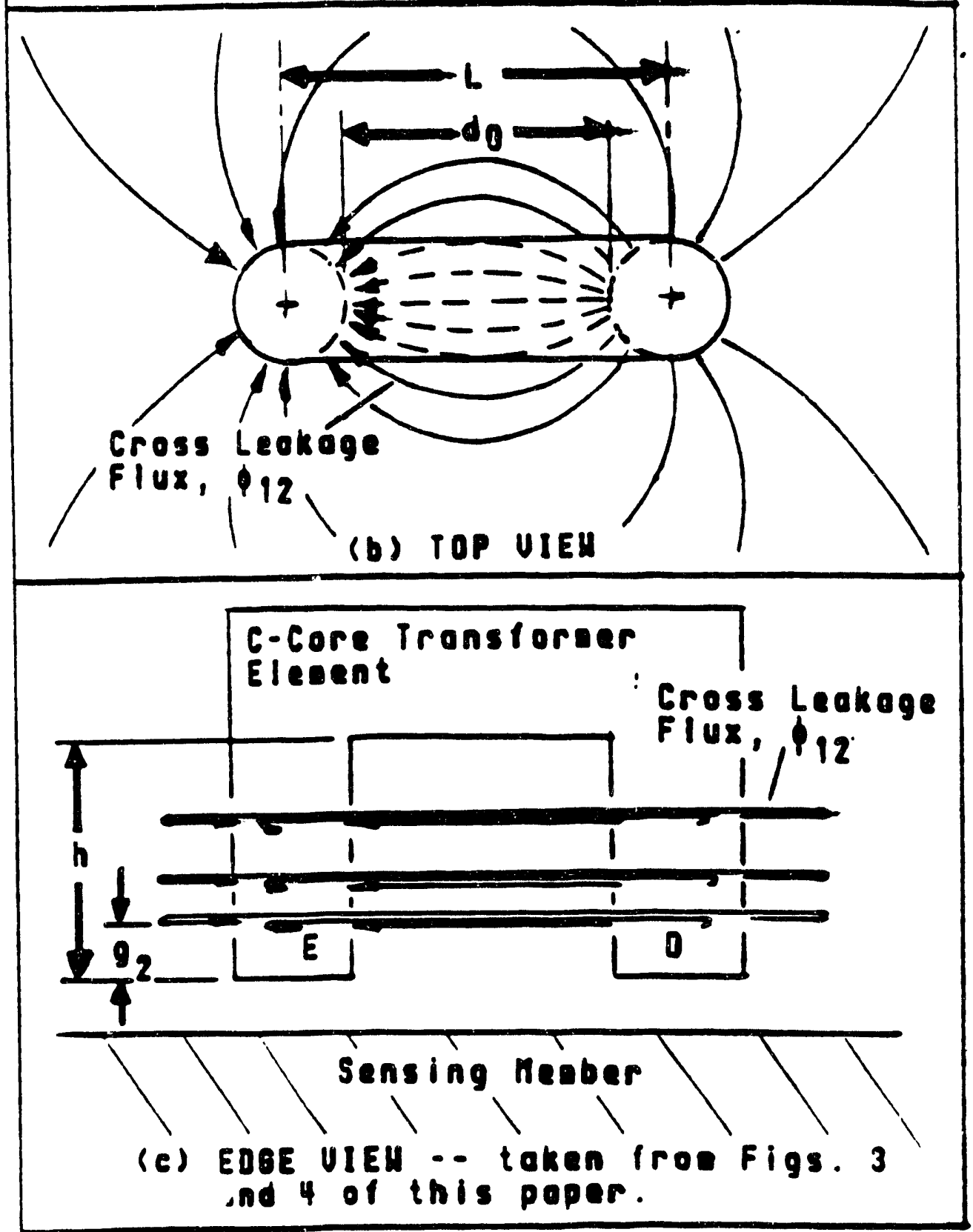

Fig. 7 Diagrams of varius lengths and distances associated with the sensor pole configuration. (after Fleming ${ }^{62}$ ) 
all the other permeances can be obtained, one can obtain $\mathrm{Z}=\mathrm{Z}\left(\mathrm{H}_{\max }\right)$.

To finish the calculation, we evaluate $P_{12}$ and $P_{\text {gaps }}$. Following Fleming ${ }^{62}$, we have

$$
P_{12}=\mu_{0}\left(h-g_{2}\right) g(u),
$$

where $\mathrm{h}$ is the length of a core arm, as in Fig. 7. The length $g_{2}$ is given by ${ }^{62}$

$$
g_{2}=d_{0} / \pi-G_{\text {avg }}
$$

where $G_{\text {avg }}$ is the average value of the air gaps associated with the two core arms. The air gap permeance is given by

$$
P_{\text {gaps }}=\frac{1}{n_{\text {gaps }}},
$$

where

$$
R_{\text {gaps }}=\left(\rho_{G}^{D}\right)^{-1}+\left(P_{G}^{E}\right)^{-1} \text {, }
$$

where for pole $\mathrm{E}$ or pole $\mathrm{D}$, one has

$$
P_{G}=P_{0}+P_{1}+P_{2}
$$

The three separate contributions to the permeance $P_{\mathrm{G}}$ refer to fluxes across three separate paths, as in seen in Fig. 8. $\rho_{o}$ refers to the flux going directly across the gap, $\rho_{1}$ to flux leaking into the specimen from the pole edge, and $P_{2}$ to flux leaking into the specimen from the sides of the core arm. These three contributions are as follows: ${ }^{62}$

$$
\begin{gathered}
P_{0}=\mu_{0} A / G, \\
P_{1}=0.528 \mu_{0} 2 \pi(r+G / 2),
\end{gathered}
$$




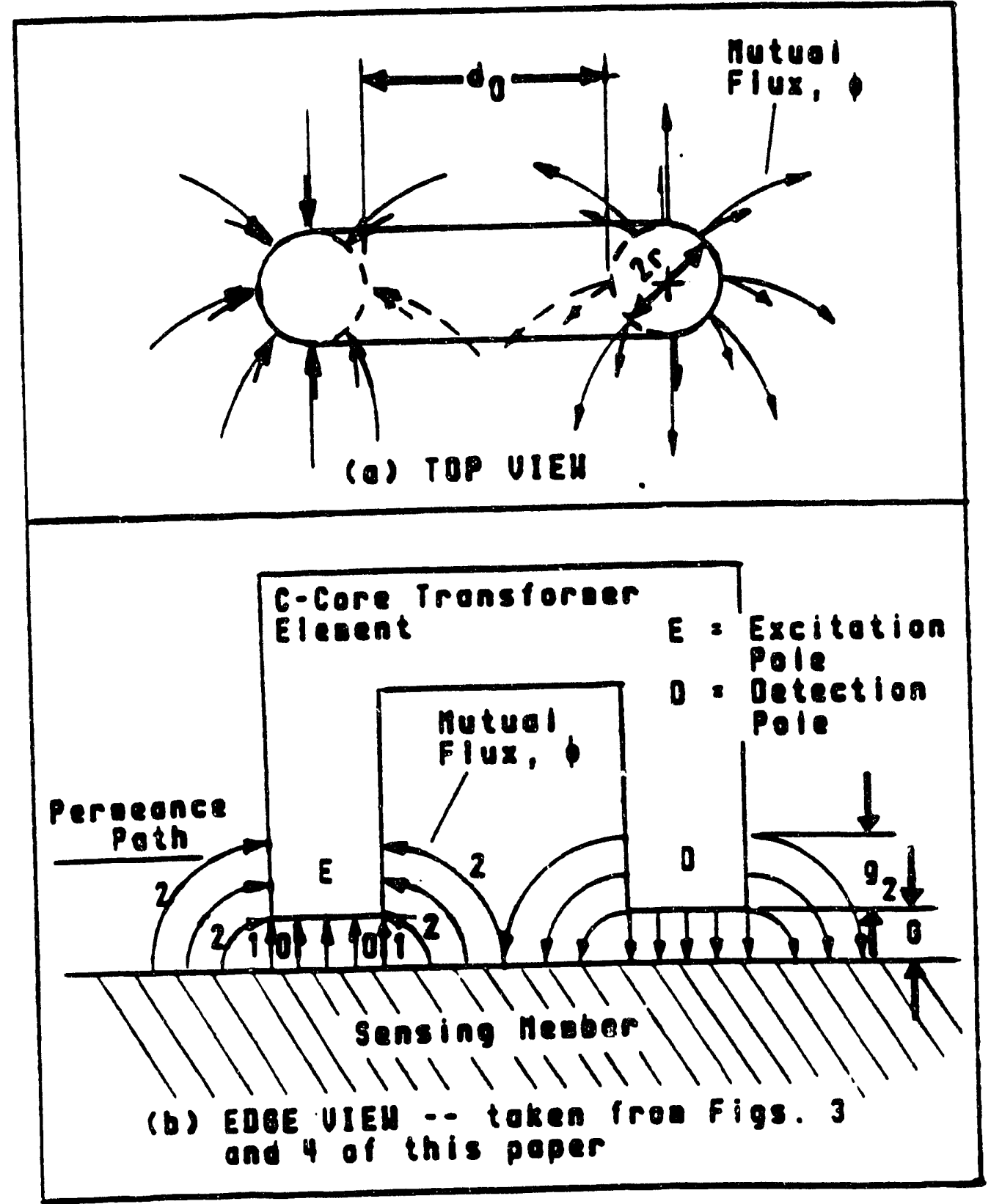

Fig. 8 Flux paths from core arm to specimen as categorized into three regions. 


$$
P_{2}=4 \mu_{0}\left[r+\sqrt{G\left(g_{2}+G\right)}\right] \ln \left(1+g_{2} / G\right),
$$

where $A=b^{2}$ is the pole face area, $G$ is the gap distance between pole face and sample, and $r$ is the effective radius of the pole.

The last $p$ :rmeance needed is $P_{3 A}$, the permeance due to eddy currents. This is more difficult to evaluate. Fleming depicts $P_{3 A}$ as ${ }^{62}$

$$
P_{3 A}=\mu_{0} h_{A} g(u),
$$

where $h_{A}$ is an effective valie of the flux field height, with the constraint that $h_{A}>\delta^{\prime}$ but with the additional constraint that $\boldsymbol{P}_{3 \mathrm{~A}}<\boldsymbol{P}_{\mathrm{s}}$, since $\mu_{0}<<$. Obviously, $\boldsymbol{P}_{3 \mathrm{~A}}$ is not well-defined and could cause problems in the analysis, compelling us to evaluate $P_{3 \mathrm{~A}}$ within certain limits and compelling us to evaluate $\mathrm{Z}$ within those same limis.

We anticipate that we will still be able to use Fleming's sensor model as a tool for extracting information about the magnetic properties of the specimen from the sensor signal.

\section{B. Experimental Tests of the Indirect Sensor}

Two types of sensers will be tested. The first sensor is depicted in Fig. 6. The second sensor will consist of an excitation coil wound about both arms instead of one arm, and a detection coil wound tightly at the end of one of the arms. (see Fig. 9) The rationale for the second sensor is that the flux linking the detection coil ought to be essentially the same as in the specimen. It is possible that because of this characteristic, the sensor model may not be needed for such a sensor, and a direct measurement of the flux in the specimen may be made with the second sensor. Nevertheless, both sensors will be analyzed using the sensor model.

Adjustments in the sensor model will be made for analysis of the second sensor. One adjustment is that the factor of $1 / 3$ will be changed into $2 / 3$ is eq. (21b), as indicated by Roters. ${ }^{71}$

Predictions of the sensor model will be compared to experimental measurements made with both sensors. Based on comparisons between experimental data and the sensor modei, cne of the two sensors will be selected for the magnetic measurements on the sperimen undergoing biaxial stress.

In accumulating data on the test sensors, experimental data will be collected under uniaxial stress on two test specimens - one with a width corresponding to that of the sensor pole pieces; the other with a width which is four times that of the pole width. Uriaxial stress will be used to test the sensors because under uniaxial stress, it will also be possible to wrap a coil around the test specimens and so obtain the flux density in the specimen. In this way, the true flux density in th: test specimen can be compared to measurements made with the test sensors on the two differently shaped specimens. This too will enable us to evaluate which of the test sensors to select. 


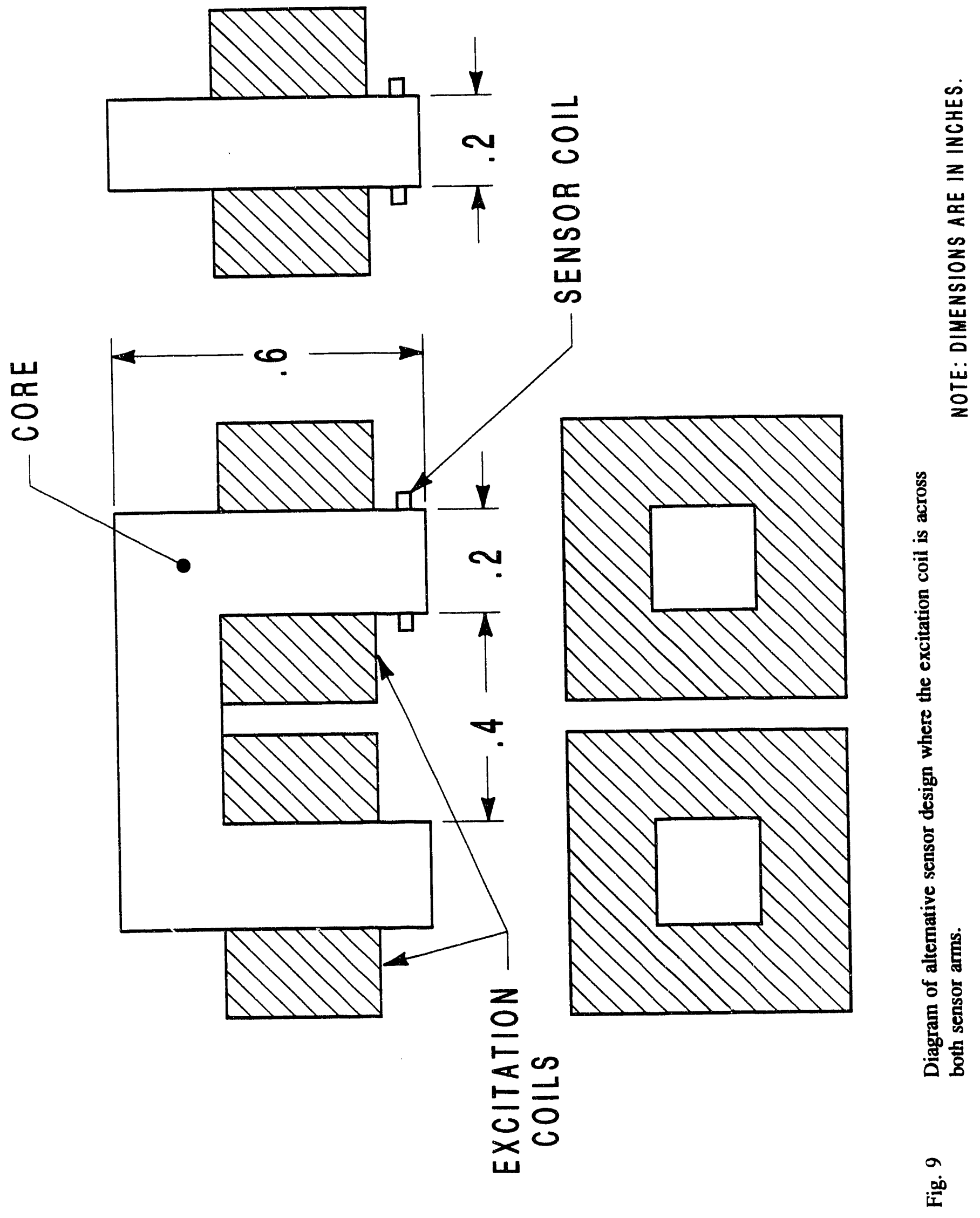




\section{SPECIMEN SHAPE DESIGN VIA FINITE ELEMENT STRESS ANALYSIS MODELING}

Our first attempt at a cruciform specimen shape design was to try the design of Kashiwaya. ${ }^{44.52}$ This involved using a specimen of uniform thickness with loading pin holes in each arm and with circular-shaped indentations in the corners where the arms join (see Fig. 10).

Fig. 11 shows the Mises stress distribution for the Kashiwaya cruciform using finite element modeling in a case where the arms are loaded biaxially with equal stresses. The Mises stress at a point is defined as $\Sigma_{\mathrm{ij}} \sigma_{\mathrm{ij}} \sigma_{\mathrm{ij}} / 2$, and so denotes the effective magnitude of all of the contributing strusses taken together at a point. It is noted that the stress distribution shows large concentrations of stress not only at the loading pin holes but also in the vicinity of the circular indentations. Furthermore, these stress consentrations are very close together, which produces a weak region in the specimen. This indicates the strong likelihood of failure at higher levels of loading at the places where the stress is concentrated. This potential for failure thus limits the maximum amount of loading that can be applied.

To provide a more uniform stress distribution in the central region where the arms join, the corners were smoothed into $90^{\circ}$ circular arcs which joined tangentially to each arm. In addition, to strengthen the region around the loading pin holes, the region was made twice as thick as the central region of the cruciform specimen. The transition from loading pin hole to central region was not a step, but rather a curved surface from one region to the other. Fig. 12 shows a side view of two cruciform arms. Only half the total thickness is shown. The dip into the central region from the loading pin hole region is clearly identified. Depicted in the diagram with color codes is the amount of stress $\sigma_{z z}$ in the $z$-direction perpendicular to the plane of the cruciform. It is seen that the stress $\sigma_{z z}$ around the loading pin holes is of relatively low magnitude and that the largest amount of stress in the z-direction occurs in the transition region from the loading pin hole to the central region. This suggests the possibility of buckling under compressive stress at that transition region; so in our experiment, we will need to use low compressive stress magnitudes.

Figs. 13 and 14 display respectively $\sigma_{x x}$ and $\sigma_{y y}$ in the plane of the cruciform. Stress still concentrates at the loading pin holes, but now the region around the hole is stronger because it is thicker. There is also an accumulation of stress in the corner region in the general area where the circular arc joins tangentially to the cruciform arm. However, the accumulation of stress is not as concentrated as it would have been if Kashiwaya's shape were used.

Having found a better test shape from the point of view of distributing the stress, the next step was to look at the central region and check for uniformity of the distribution in a 1:1 load situation. Thus, Fig. 15 displays a one-inch square quadrant taken out of the central region. The ratio $\sigma_{y y} / \sigma_{x x}$ is color-coded in the display. It is seen that this ratio varies from 1.08 to 0.92 in a center region that is $0.75^{\prime \prime}$ square. Thus, the stress can be said to be uniform in such a region to within $\pm 8 \%$. Our probe will be designed to fit across that region with a distance of $0.6 \mathrm{in}$. between pole centers. Thus, we can expect an error of the order of less than $\pm 8 \%$, owing to slight nonuniformity of the stress distribution.

This type of analysis was not reported by any other authors in the discussion of biaxial stress experiments. 


\section{Thickness: $7 \mathrm{~mm}$}

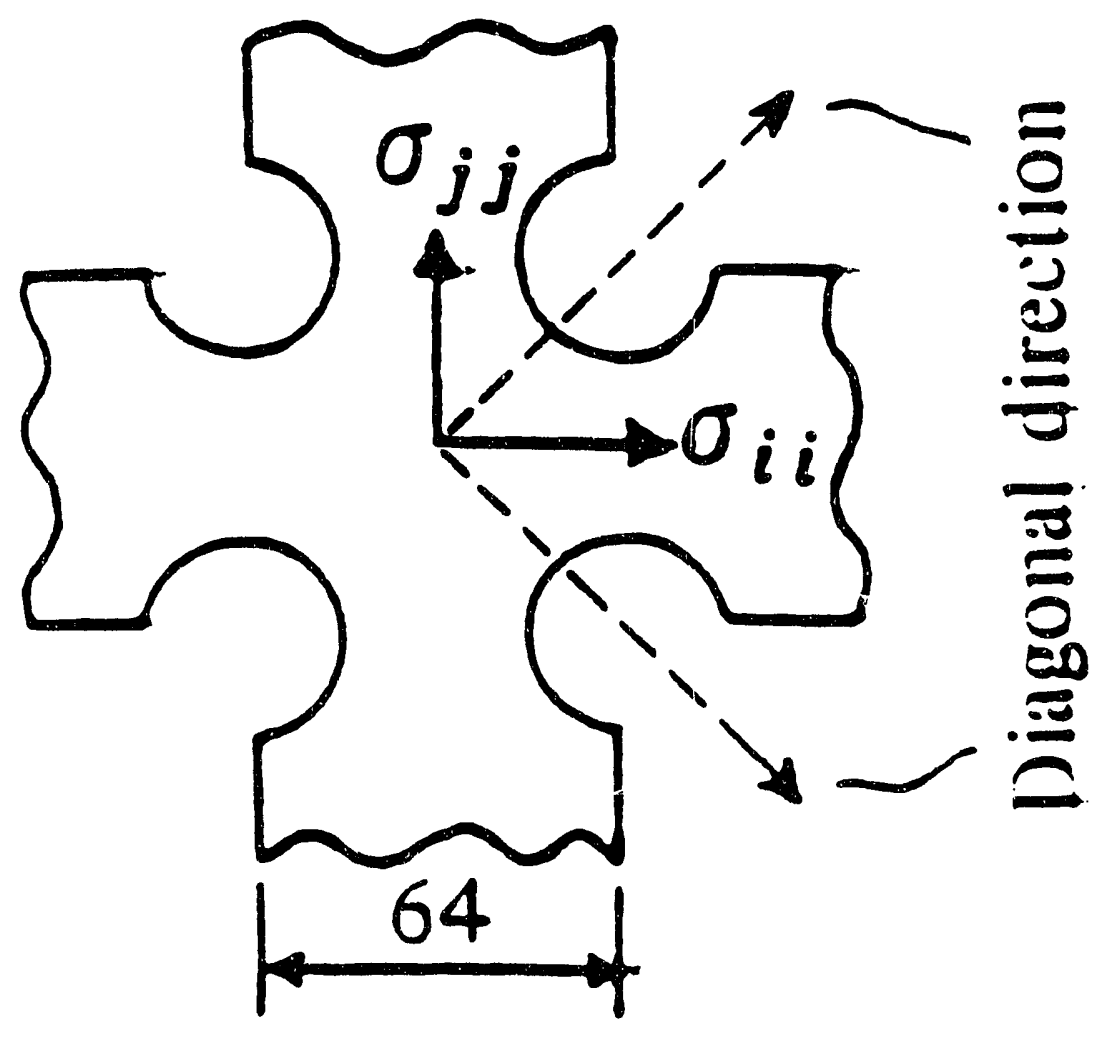

Fig. 10 Diagram of Kashiwaya et al's cruciform specimen. (after Kashiwaya ${ }^{52}$ ) 


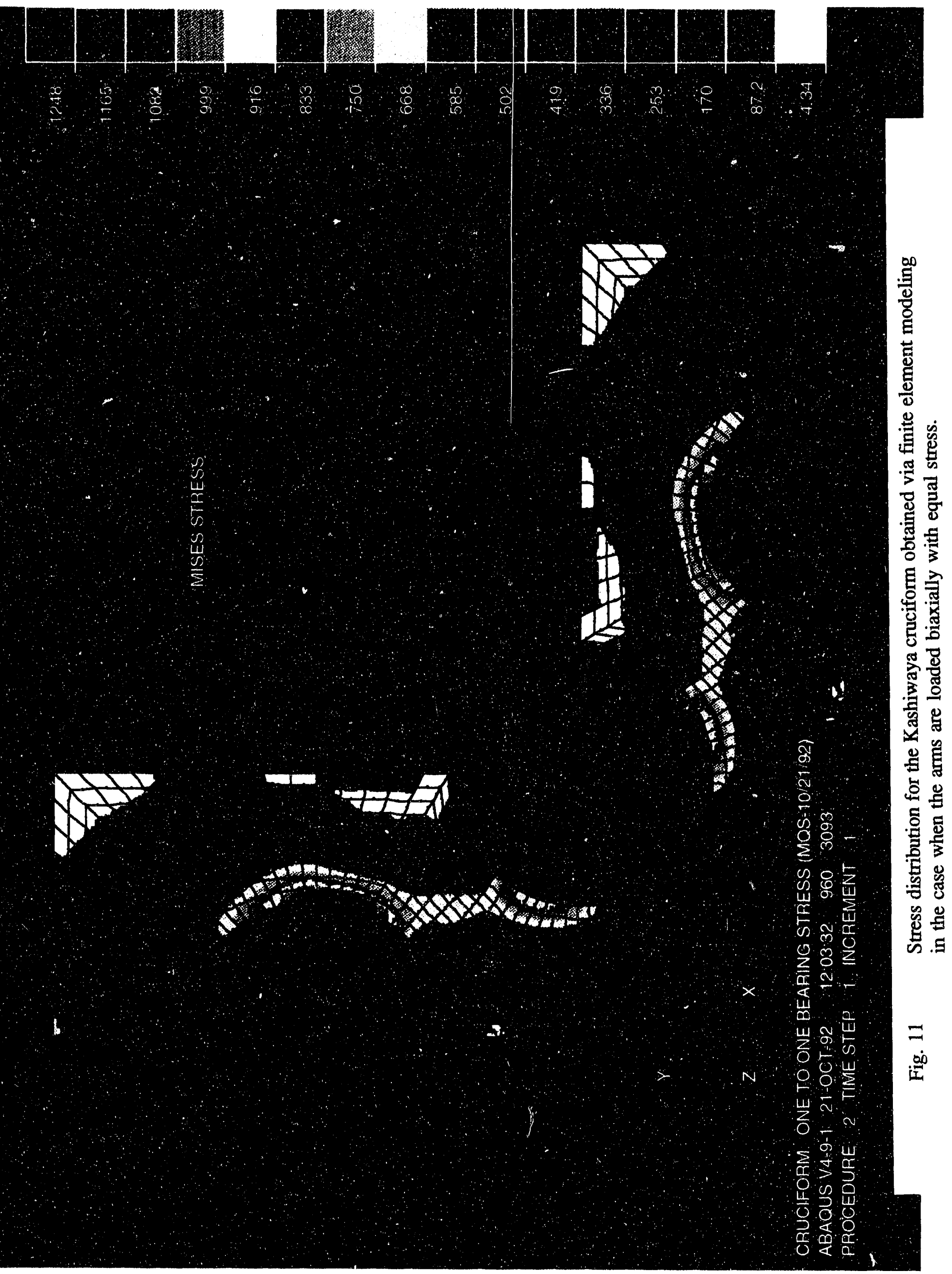




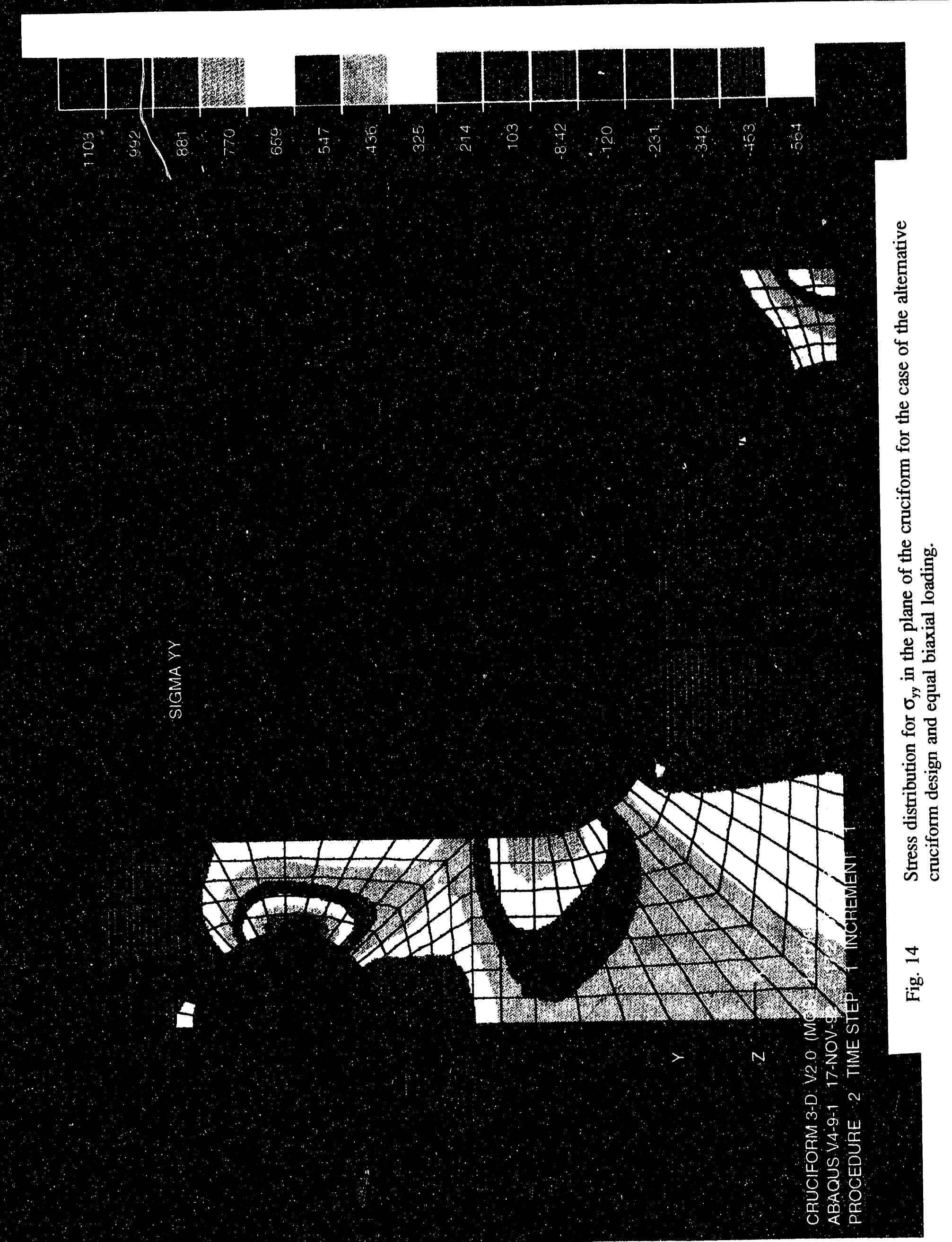




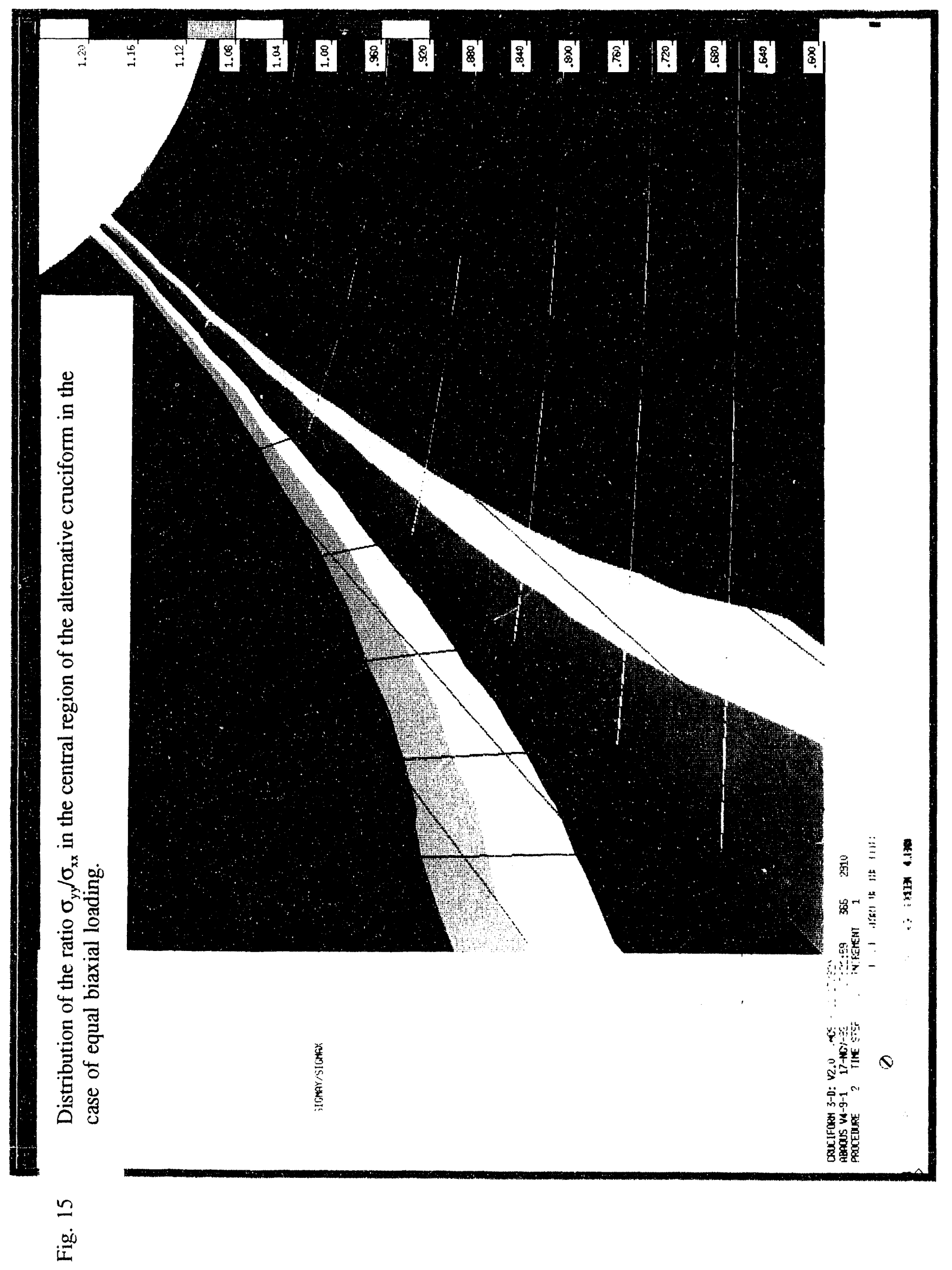


Despite the nonideal situation of having a slightly nonuniform stress distribution, the second design shape nevertheless is sufficiently uniform in its central stress distribution to enable the experiments to proceed. Two cruciform specimens of the second design shape are currently being machined. Also being machined are uniaxial specimens of the same material as the cruciforms. These uniaxial specimens will be used to test sensor design, as described in Section III B. 


\section{CONSTRUCTION OF THE BIAXIAL LOADING APPARATUS}

The biaxial stressing fixture is composed of two units, the $x$-axis and the $y$-axis. (see Fig. 16) The fixture is designed so that either tensile or compressive loads can be applied to a test specimen. The two units are designed to apply the biaxial loads at 9()-degrees in relation to each other. The loads may be tension or compression in both directions or tension in one direction and compression in the other. The load is applied by an independent hydraulic cylinder with hand pump and gauge for each axis.

Each unit is similar in construction and consists of the tail plate, head plate, load cylinder, 2 clevises, and 4 rods. The head and tail plates are separated by the 4 rods. There are 8 bolts which attached to the head plate. One clevis is attached to the cylinder and the other to the tail plate. The $y$-axis unit is slightly smaller than the $x$-axis unit in vertical height. This allows the $y$-axis unit to be suspended between the $x$-axis unit rods by a housing containing linear bearings. This arrangement allows the $y$-axis to travel freely in both the $x$ and $y$-axis directions. The test specimen is mounted between the clevises and pressure is applied to the cylinder to stress the specimen.

The hand pump/cylinders are 25-ton units which means that a maximum of $50,000 \mathrm{lbs}$ of force can be applied to the specimen. The structure is designed to accommodate this force in tensile stress on the specimen. However, stainless steel bolts were used to hold the rods in place and the compressive load on the specimen should be limited to $25,000 \mathrm{lbs}$ to maintain a safety factor greater than 2 .

Application of tensile stress is accomplished as follows. As load is applied to the cylinder, it pulls the clevis and specimen, thereby applying a reaction load to the head and tail plates, which are prevented from moving by the 4 separating rods which are loaded in compression. If the load causes the specimen to move, the $y$-axis can compensate by moving with the specimen in either the $\mathrm{x}$-axis or $\mathrm{y}$-axis direction.

The system works the same for compressive stress as for tensile stress except that the cylinder is pushing the clevis and specimen, which reverses the force direction on the head and tail plates and places tension on the 4 separating rods instead of compression. 


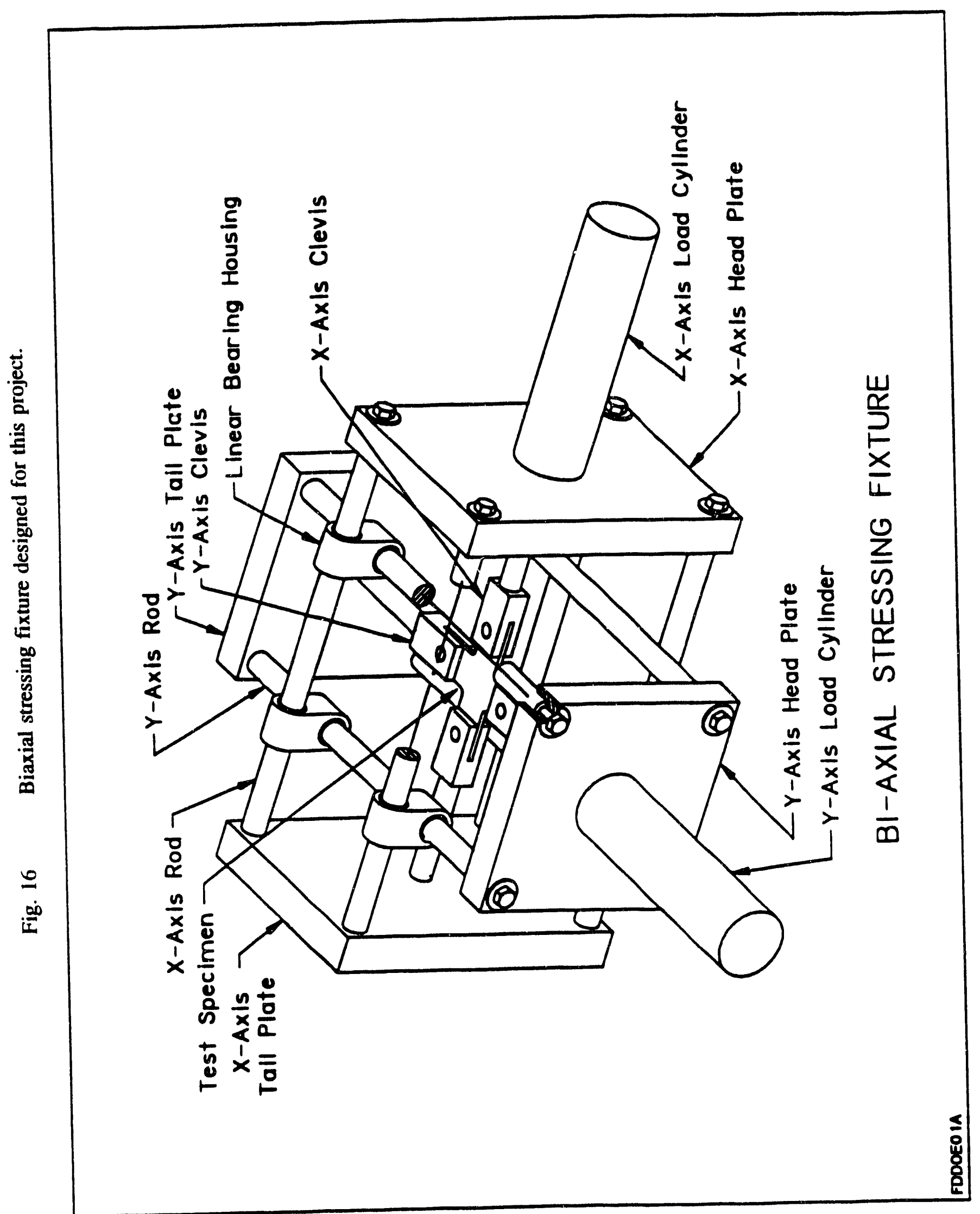




\section{SUMMARY AND DISCUSSION OF FUTURE PLANS}

\section{A. Experimental}

Up to this point, we have been doing the preparatory work needed for measurements of magnetic property changes in a specimen due to biaxial stresses.

One consideration has been interpretation of the measurements made with an indirect sensor placed on the surface of the specimen. A sensor model has been adopted that can be used together with the magnetomechanical hysteresis model (or other such models) to predict sensor readings for specimens in varying degrees of biaxial stress. Experimentally, two sensors of different design are in the process of construction.

In the latter half of this second year, the two sensors will be experimentally tested against the predictions of the sensor model for the case of uniaxial stress. For this purpose, two steel plates specimens with loading pin holes on the ends for tensile testing will be used. One plate will have a gauge section with width equal to the width of the pole pieces and the other, a width equal to four times that of the pole pieces. This should provide a test of the effects of flux spreading into the sample. At the same time, a secondary coil can be wrapped around a cross-section of the plate for measurement of true flux density in the specimen. This measurement will be compared to the measurement made with the indirect sensor for different stresses. The measurements will also be compared to predictions made with the sensor model.

Other preparatory considerations have been design of the cruciform specimen shape and construction of the loading apparatus. These phases are completed, and two cruciform specimens are currently being made, one to be used as a backup.

It is planned that measurements of magnetic property changes for different biaxial stresses will be carried out in the latter half of this second year. Strain gauges will be attached to the specimen to verify local magnitudes of the biaxial stresses in the region of the sensor readings. Hysteresis loops and nonlinear harmonics will be monitored. Coercivity changes, remanence changes, permeability changes, maximum flux density changes and harmonic amplitudes will be checked for their variation with respect to biaxial stress. The following cases will be examined:

1) $\mathrm{H} \| \sigma_{1}$-axis, $\perp \sigma_{2}$-axis

2) $H \| \sigma_{2}$-axis, $\perp \sigma_{1}$-axis

3) $\mathrm{H}$ at $45^{\circ}$ with respect to both axes.

The third case is of special significance because of the prediction by the magnetomechanical hysteresis model that the magnetic property changes will be proportional to changes in $\sigma_{1}+\sigma_{2}$ when the field is at $45^{\circ}$.

In the third year, it will be determined from analysis of second year results whether a measurement of magnetic property changes with $\mathrm{H}$ perpendicular to both stress axes is needed. If necessary, a new larger sensor shaped like a C-clamp will be designed and measurements will be made with it. The larger sensor will be required if the center thickness of the cruciform test specimen is to fit between the pole pieces of the sensor. 
Also, in the third year, Barkhausen measurements, MIVC measurements, and magabsorption measurements are planned. The reader will recall that these same measurements were done in the case of the neutron embrittlement work in the first year and the reader is referred to the first year report for a detailed discussion of the measurement techniques.

\section{B. Modeling}

Up to this point, two models have been developed for magnetic property changes due to biaxial stresses.

In the magnetomechanical hysteresis modeling, it was additionally assumed that magnetic changes due to biaxial stresses involve superposing changes that would occur if the two stresses were each uniaxial. This modeling resulted in the striking predictions that:

1) The magnetic properties $\left(H_{c} / H_{\max }, B_{\sqrt{ }} / \mu_{0} H_{\max }, B_{\max } / \mu_{o} H_{\max }\right.$ and $\left.\mu_{c}\right)$ all vary as $\sigma_{1}+\sigma_{2}$ when the field is at $45^{\circ}$ with respect to both stress axes.

2) The differences ()$_{\perp}-()_{1}$ vary as $\sigma_{2}-\sigma_{1}$, where ()$_{\perp}$ and ()$_{1}$ represent the magnetic properties with the field perpendicular and parallel respectively to the $\sigma_{1^{-}}$ axis.

However, recent work by Kashiwaya et $\mathrm{al}^{42,44,52}$ suggests that the magnetomechanical hysteresis model and superposition of stresses is not the whole story. Employing Kashiwaya's observations, the Schneider-Richardson model was modified in a separate project, and the modified model was able to qualitatively account for magnetic property changes under biaxial stress, as measured by $R$. Langman (see Appendix C).

In the remainder of the second year and in the third year, the magnetomechanical hystersis model will be modified to account for the considerations used by the new modified SchneiderKashiwaya model. In the process, it will be necessary to incorporate the variations due to the Ewing/Villari effect ${ }^{60.61}$ into the magnetomechanical hysteresis model. It is expected that the results will lead to the synthesis of all three models -.. magnetomechanical hysteresis model, Schneider model, and Kashiwaya model.

Predictions of the final model will be compared to experimental measurement also made on this project.

In addition, the prediction of Barkhausen amplitude changes, MIVC changes, and magabsorption changes will also be evaluated, using the models already developed for these changes (see Appendix C, first year report and Refs. 12 and 15).

One more modeling task that will be done if time permits is to develop a better microstructural model for the magnetic material parameter changes that would occur due to neutron embrittlement. The purpose would be to try the distinguish the similarities and differences between neutron embrittlement and creep damage. 


\section{REFERENCES}

1. R. Becker and M. Kersten, Z. Physik 64. 600 (1930).

2. W. F. Brown, Phys Rev. 75, 147 (1949).

3. R. R. Birss, IEEE Trans. Magn. $\underline{1}, 113$ (1971).

4. C. S. Schneider and E. A. Semcken, J. Appl. Phys. $\underline{52}, 2425$ (1981).

5. M. K. Spano, K. B. Hathaway, and H. T. Savage, J. Appl. Phys. $\underline{53}$, 2667 (1982).

6. D. L. Atherton and D. C. Jiles, IEEE Trans. Magn. $\underline{19}, 2021$ (1983).

7. C. S. Schneider and M. Charlesworth, J. Appl. Phys. $\underline{57}, 4198$ (1985).

8. H. Kwun, J. Magn. Magn. Mater. 49, 235 (1985).

9. M. J. Sablik, H. Kwun, G. L. Burkhardt, and D. C. 'iles, J. Appl. Phys. 61 , 3799 (1987).

10. IM. J. Sablik, G. L. Burkhardt, H. Kwun and D. C. Jiles, J. Appl. Phys. $\underline{63}$, 3930 (1988).

11. M. J. Sablik and D. C. Jiles, J. Appl. Phys. 64, 5402 (1988).

12. M. J. Sablik, W. L. Rollwitz, and D. C. Jiles, Proc. 17th Symposium on NDE, San Antonio, TX (NTLAC, Southwest Research Institute, 1989), pp. 212-23.

13. M. J. Sablik, Nondestr. Testing and Evaluation $\underline{5}, 45$ (1989).

14. M. J. Sablik, D. C. Jiles and L. Barghout, J. Appl. Phys. 67, 5019 (1990) (abstract only).

15. M. J. Sablik and H. Kwun, J. Appl. Phys. $\underline{69}$, 5791 (1991).

16. M. J. Sablik and S. W. Rubin, J. Magn. Magn. Mater. 104-7, 392 (1992).

17. C. S. Schneider, P. Y. Cannell, and K. T. Watts, IEEE Trans. Magn. 28, 2626 (1992).

18. M. J. Sablik and D. C. Jiles, submitted to IEEE Trans. Magn.

19. M. J. Sablik, S. W. Rubin, L. A. Riley, D. C. Jiles, D. A. Kaminski, and S. B. Biner, submitted to J. Appl. Phys.

20. R. M. Bozorth and H. J. Williams, Rev. Mod. Phys. $\underline{17}$, 72 (1945).

21. D. J. Craik and M. J. Wood, J. Phys. D $\underline{3}$, 1009 (1970).

22. I. Preece and R. Thomas, Digest Intermag Conf., Denver, CO, Apr. 1971, p. 15.7. 
23. R. R. Birss, C. A. Faunce, and E. D. Issac, J. Phys. D 4., 1040 (1971).

24. N. A. Vekser, A. S. Smirnov, A. Yu Fadeev, M. M. Shel, V. F. Torkunov, and V. A. Gudyrya, Sov. J. NDT, 11,183 (1975).

25. A. Zentko, L. Potocky, T. Tima, T. Svec, R. Mlynek, and D. Cech, J. Magn. Magn. Mater. 19,25 (1980).

26. R. Langman, NDT International $\underline{14}, 255$ (1981).

27. V. F. Novikov and V. A. Izosimov, Phys. Met. Metall. $\underline{58}, 57$ (1984).

28. R. Langman, IEEE Trans. Magn. 21, 1314 (1985).

29. H. Kwun and G. L. Burkhardt, Proc. 2nd National Seminor on NDE of Ferromagnetic Materials, Houston, TX (Dresser Industries, 1986).

30. H. Kwun and G. L. Burkhardt, J. Appl. Phys. 61, 1576 (1987).

31. H. Kwun and G. L. Burkhardt, NDT International 20, 167 (1987).

32. D. L. Atherton and T. S. Rao, J. Appl. Phys. 62, 2914 (1987).

33. D. L. Atherton, T. S. Rao, and M. Schonbachler, IEEE Trans. Magn. 24, 2029 (1988).

34. D. C. Jiles, T. T. Chang, D. R. Hougen and R. Ranjan, J. Appl. Phys. $\underline{64,} 3620$ (1988).

35. P. Garikepati, T. T. Chang, and D. C. Jiles, IEEE Trans. Magn. 24, 2922 (1988).

36. D. C. Jiles, Rev. of Progress in Quant. NDE $\underline{9}, 1821$ (1990).

37. H. Kwun, G. L. Burkhardt, and M. E. Smith, Rev. Progr. Quant. NDE 9, 1895 (1990).

38. D. L. Atherton and V. Ton, IEEE Trans. Magn. 26, 1153 (1990).

39. D. L. Atherton and V. Ton, IEEE Trans. Magn. 26, 1157 (1990).

40. M. K. Devine, S. Hariharan, L. J. H. Brasche and D. C. Jiles, Rev. Progr. Quant. NDE 10B, 2021 (1991).

41. R. A. Langman, NDT International $\underline{15}, 91$ (1982).

42. K. Kashiwaya, H. Sakamoto and Y. Inoue, QR of RTRI (Japan) 29, 126, (1988).

43. Y. Furuya, H. Shimada, and Y. Ito, VI Intl. Congress on Explt. Mechanics, Portland, OR 1988, Vol. 1 (Soc. for Exptl. Mech (SEM), Bethel, Conn., 1988), pp. 30-35.

44. K. Kashiwaya, H. Sakamoto, and Y. Inoue, VI Intl. Congress on Exptl. Mechanics, Portland, 
OR, 1988, Vol. 1 (SEM, Bethel, Conn, 1988), pp. 428-33.

45. C. Jagadish, L. Clapham, and D. L. Atherton, J. Phys. D $\underline{23}, 443$ (1990).

46. R. A. Langman, IEE Trans. Magn. 26, 1246 (1990).

47. D. J. Buttle. W. Dalzell, C. B. Scruby, and R. A. Langman, in Rev. Prog. Quant. Nondestr. Eval., ed. D. O. Thompson and D. E. Chimenti (Plenum, NY, NY, 1990), pp. 1879-85.

48. G. L. Burkhardt, H. Kwun, A. E. Crouch and D. A. Desnoyer, in Damage Assessment, Reliability and Life Prediction of Power Plant Components, PVP-vol. 193, NDE-vol. 8, Proc. 1990 Pressure Vessels and Piping Conference, Nashville, TN, June 1990 (ASME, NYC, 1990), p. 95.

49. R. A. Langman, Nondestr. Testing-Australia 27, 124 (1990).

50. K. Fuchimoto, Y. Ogawa, S. Oka, and K. Shimizu, Proc. 1992 Intl. Gas Research Conf., pp. 25-33.

51. C. S. Schneider and J. M. Richardson, J. Appl. Phys. 53, 8136 (1982).

52. K. Kashiwaya, Jpn. J. Appl. Phys. 30, Pt. 1, 2932 (1991).

53. K. Kashiwaya, Jpn J. Appl. Phys. 30, Pt. 1, 237 (1992).

54. M. J. Sablik, H. Kwun, W. L. Rollwitz and D. Cadena, "A Proposal for Application of Magnetomechanical Hysteresis Modeling to Magnetic Techniques for Monitoring Neutron Embrittlement and Biaxial Stresses," Proposal \#15-9841 (Southwest Research Institute, March, 1990).

55. A. E. H. Love, A Treatise on the Mathematicl Theory of Elasticity, 4th ed. (Dover, NY 1944), pp. 103-8, 155, 162-3.

56. F. W. Sears, Thermodynamics (Addison Wesley, Reading, MA, 1953) pp. 308-310.

57. S. Chikazumi and S. H. Charap, Physics of Magnetism, (Krieger Publ. Co., Malabar, FL, 1984), pp. 170-3.

58. R. A. Langman, IEEE Trans. Magn. 17, 1159 (1981).

59. R. A. Langman, NDT Internatl. 16, 59 (1983).

60. E. Villari, Ann. Phys. Chem. 126,87 (1865).

61. J. A. Ewing, Magnetic Induction in Iron and Other Materials, (Van Nostrand, NY, 1892), pp. 198-200. 
62. W. J. Fleming, SAE Trans., Paper 890482, (1989), pp. 519-538.

63. W. J. Fleming, SAE Trans., Paper 890483 (1989), pp. 539-553.

64. W. J. Fleming, IEEE Trans. on Vehicular Techn. $\underline{38}$, 159 (1989).

65. W. J. Fleming, SAE Trans. Paper 900264 (1990), pp. 393-420.

66. W. J. Fleming, SAE Trans. Paper 910857 (1991), pp. 1211-42.

67. R. M. Bozorth, Ferromagnetism, (Van Nostrand, NY 1951), pp. 769-783.

68. S. Ramo and H. Whinnery, Fields and Waves in Communication Electronics, (Wiley, NY , 1965), pp. 288-9.

69. B. Chalmers and I. Woolley, Proc. IEE 119,1301 (1972).

70. H. McConnell, AIEE Trans. Part I, $\underline{73}, 226$ (1954).

71. H. C. Roters, Electromagnetic Devices (Wiley, NY, 1941), pp. 97-8.

Regints + Prepients Rerroved 

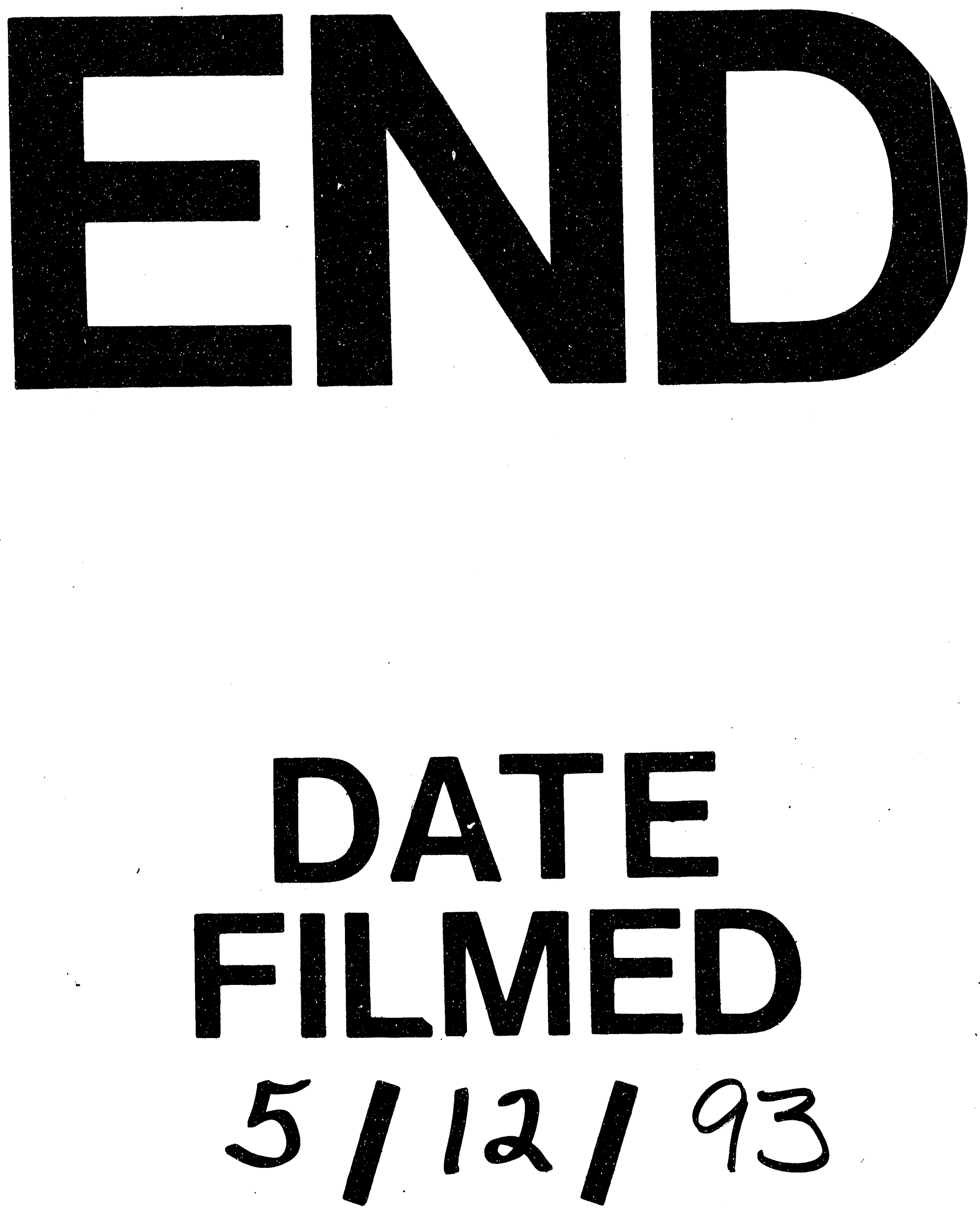

1 
